\title{
Public and health professional epidemic risk perceptions in countries that are highly vulnerable to epidemics: a systematic review
}

Nada Abdelmagid ${ }^{1 *}$ (D) Francesco Checchi $^{2}$ and Bayard Roberts ${ }^{1}$

\begin{abstract}
Background: Risk communication interventions during epidemics aim to modify risk perceptions to achieve rapid shifts in population health behaviours. Exposure to frequent and often concurrent epidemics may influence how the public and health professionals perceive and respond to epidemic risks. This review aimed to systematically examine the evidence on risk perceptions of epidemic-prone diseases in countries highly vulnerable to epidemics.

Methods: We conducted a systematic review using PRISMA standards. We included peer-reviewed studies describing or measuring risk perceptions of epidemic-prone diseases among the general adult population or health professionals in 62 countries considered highly vulnerable to epidemics. We searched seven bibliographic databases and applied a four-stage screening and selection process, followed by quality appraisal. We conducted a narrative metasynthesis and descriptive summary of the evidence, guided by the Social Amplification of Risk Framework.

Results: Fifty-six studies were eligible for the final review. They were conducted in eighteen countries and addressed thirteen epidemic-prone diseases. Forty-five studies were quantitative, six qualitative and five used mixed methods. Forty-one studies described epidemic risk perceptions in the general public and nineteen among health professionals. Perceived severity of epidemic-prone diseases appeared high across public and health professional populations. However, perceived likelihood of acquiring disease varied from low to moderate to high among the general public, and appeared consistently high amongst health professionals. Other occupational groups with high exposure to specific diseases, such as bushmeat handlers, reported even lower perceived likelihood than the general population. Among health professionals, the safety and effectiveness of the work environment and of the broader health system response influenced perceptions. Among the general population, disease severity, familiarity and controllability of diseases were influential factors. However, the evidence on how epidemic risk perceptions are formed or modified in these populations is limited.
\end{abstract}

Conclusions: The evidence affords some insights into patterns of epidemic risk perception and influencing factors, but inadequately explores what underlies perceptions and their variability, particularly among diseases, populations and over time. Approaches to defining and measuring epidemic risk perceptions are relatively underdeveloped.

Keywords: Risk perception, Epidemic, Vulnerability

*Correspondence: nada.abdelmagid@Ishtm.ac.uk

${ }^{1}$ Faculty of Public Health \& Policy, London School of Hygiene \& Tropical

Medicine, 15-17 Tavistock Place, London WC1H 9SH, UK

Full list of author information is available at the end of the article original author(s) and the source, provide a link to the Creative Commons licence, and indicate if changes were made. The images or other third party material in this article are included in the article's Creative Commons licence, unless indicated otherwise in a credit line to the material. If material is not included in the article's Creative Commons licence and your intended use is not permitted by statutory regulation or exceeds the permitted use, you will need to obtain permission directly from the copyright holder. To view a copy of this licence, visit http://creativecommons.org/licenses/by/4.0/. The Creative Commons Public Domain Dedication waiver (http://creativeco mmons.org/publicdomain/zero/1.0/) applies to the data made available in this article, unless otherwise stated in a credit line to the data. 


\section{Graphical Abstract}

\section{Public and health professional epidemic risk perceptions in countries that are highly vulnerable to epidemics: a systematic review}

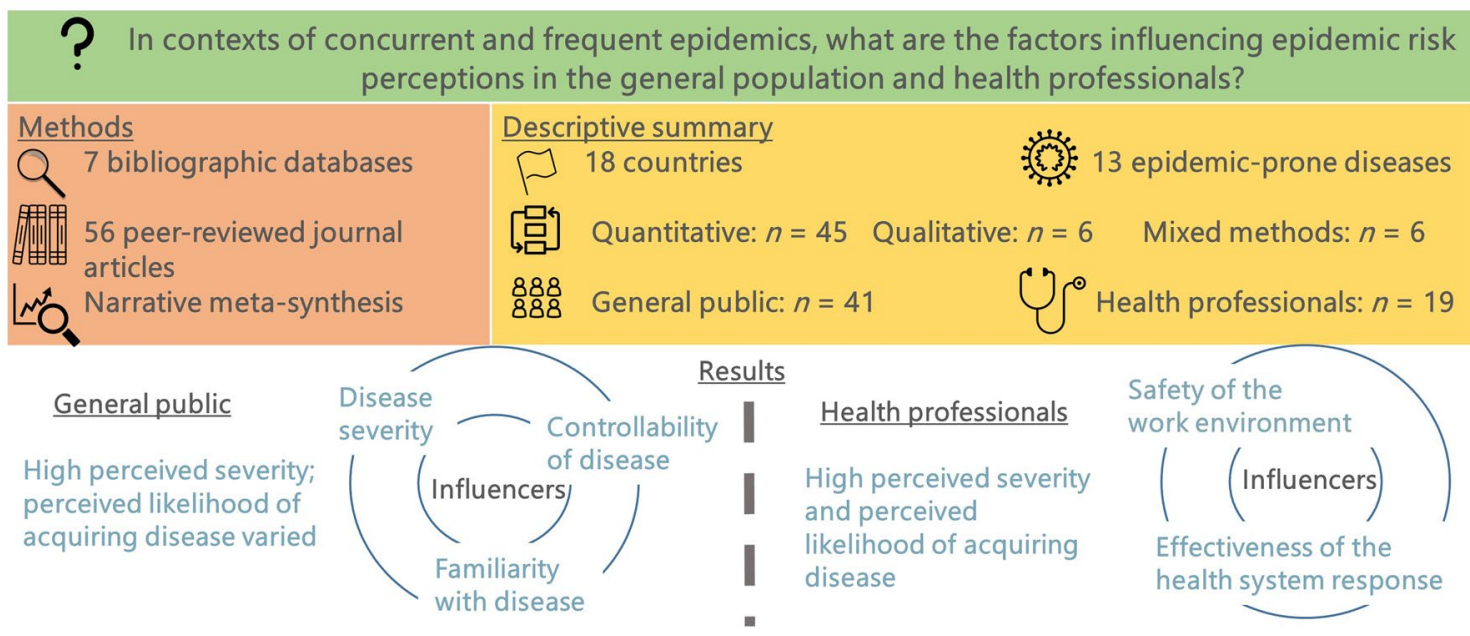

Conclusion: The evidence on how epidemic risk perceptions are formed or modified in these populations is limited

\section{Background}

Although the twenty-first century saw a rapid decline in global mortality attributable to infectious diseases, they continue to account for high morbidity and mortality in low-income countries [1]. Epidemics of infectious diseases may arise and propagate faster than before [2] due to increased social mixing and exposure to wild animal reservoirs and challenges with timely detection and containment $[3,4]$.

A 2016 analysis suggested that 22 of the 25 most epidemic-vulnerable countries are in Africa, particularly concentrated across the Sahel region, and that vulnerability correlates with recent or ongoing conflict [5]. Lowincome countries are generally the least well-prepared [6], particularly in regions at elevated risk of emerging zoonotic infections [7].

An individual's subjective judgement of a health threat-or risk perception-is central to key health behaviour change theories, including the Health Belief Model [8], the Protection Motivation Theory [9], the Extended Parallel Process Model [10], and the Risk Perception Attitude framework [11]. These theories generally assume that risk perceptions are an essential precursor of protective health behaviours. While this assumption has not been consistently borne out in individual studies, metaanalyses suggest a modest to moderate influence of risk perception on health behaviours [12-15].

Three theoretical approaches seek to explain risk perception. The psychometric paradigm in psychology theorizes that cognition and emotion play a role in the formation of risk perceptions, by influencing information processing and judgment for decision-making [16]. The cultural theory of risk in sociology and anthropology posits that risk is non-objective and perceptions are determined by an individual's sociocultural reality [17]. Among multidisciplinary models, the Social Amplification of Risk Framework (SARF) ties technical assessments of risk with psychological, sociological, and cultural perspectives, modulated by social and individual factors [18].

Risk communication is a fundamental intervention in epidemic responses, and is defined by the World Health Organization as the "the real-time exchange of information, advice and opinions between experts, community leaders, or officials and the people who are at risk", with the implicit assumption that this process will instigate appropriate individual perceptions and inform behaviour [19]. However, risk perceptions are subject to other influences [20], including individual numeracy [21], prior experiences and imminence of the threat [22].

Highly epidemic-vulnerable countries are likely to also experience insecurity, poverty and underperforming health services $[5,6]$. Here, populations and responders are often confronted with concurrent and competing risks to life, against limited resources [23]. This context is likely to influence how the general population health professionals tasked with their care and protection, perceive and make decisions about health risks. Studies in 
low-income multi-hazard contexts indicate that environmental risk perceptions and prioritisation are influenced by hazard characteristics (e.g. chronicity) [24], individual factors (e.g. socioeconomic status) [24], and collective coping capacity $[25,26]$, and that risk perceptions vary within groups and over time [26].

There is insufficient evidence on the effectiveness of epidemic risk communication interventions in low and middle-income settings [27]. A thorough understanding is required of how risk perceptions of epidemics are constructed by individuals from the general population and health professionals, the factors influencing these risk perceptions and how they interact in a context of high vulnerability to epidemics. Such insight is essential for informing effective and contextualised epidemic risk communication interventions. This review aimed to examine the existing evidence on risk perceptions of epidemic-prone diseases among the public and health professionals in highly epidemic-vulnerable countries. We also examined how risk perception has been conceptualised and measured by researchers in these settings.

\section{Methodology}

The review is designed and reported as per the PRISMA Statement [28]. The inclusion and exclusion criteria are described in Table 1.

\section{Search strategy, study screening and selection}

We searched seven bibliographic databases to cover the multiple disciplines of risk perception research: EMBASE, Global Health, MEDLINE, PsycINFO, AfricaWide Information, CINAHL Plus and Web of Science. The search terms covered three concepts: risk perception, epidemic-prone diseases, and eligible countries. Since the concept of 'risk' does not translate directly into many languages spoken in the targeted countries, we included search terms for 'risk perception' that have been used to study similar concepts, or that hold neutral (e.g. likelihood) or positive connotations (e.g. safety). We also perused related systematic reviews to identify additional synonyms for these concepts [29-31]. Additional file 1 shows the detailed list of search terms and search strategies used. The search was not limited by language although data extraction was limited to English results. The search was restricted to citations published on or after January 2011, and was conducted on 28 December 2021.

We exported all citations into EndNote (Version X9, Clarivate Analytics, Philadelphia, United States of America) for screening and selection. This phase was carried out by the first author (NA) in four stages: automatic and manual removal of duplicates, screening of titles and abstracts of search results to remove ineligible studies, reviewing the full-text articles of search results to remove ineligible studies and final paper selection. When it was unclear whether or not an item met eligibility criteria during screening, the reviewer erred on the side of caution and the item was carried into full-text reviewing. The results of the screening and selection process are presented in Fig. 1.

\section{Data extraction, quality appraisal and analysis}

We extracted the following variables from each eligible study into an Excel database: information about the epidemic-prone disease(s) under study, characteristics of study population(s), study aim and objective, concept or definition of risk perception, study design and data collection method(s), results, conclusions and quality of studies.

We assessed the quality of papers using three tools: the Appraisal tool for Cross-Sectional Studies (AXIS tool) for cross-sectional quantitative studies [32], the RATS guidelines for qualitative research [33], and the Mixed Methods Appraisal Tool (MMAT) for mixed method study designs [34]. The quality appraisal tools served to highlight the strengths and weaknesses of the studies to assist in the interpretation of the findings, but no studies were excluded following quality appraisal. We used a narrative meta-synthesis and summary of the evidence to analyse the studies, due to the heterogeneous nature of eligible study designs which did not lend itself to formal metaanalysis. We categorised eligible studies into groups as shown in Table 2.

Analysis was guided by themes from the SARF [18]. The main premise of the framework is that portrayal of a risk source (e.g. an epidemic-prone disease) and a risk event (e.g. an epidemic and its response) interacts with psychological, social, cultural and institutional processes in ways that may lead to attenuated or amplified risk perceptions $[35,36]$. The SARF provides a common terminology for comparing studies from varying disciplines, diseases and populations [37]. We described epidemic risk perceptions levels as 'high', 'moderate' or 'low' according to the scales used in individual eligible studies. We described all factors determined as associated or not associated with epidemic risk perceptions by individual eligible studies, and we organised presentation of factors by components of the SARF. Separately, we described conceptualisations and measurement approaches for each dimension of risk assessment (groups B above).

\section{Results}

Description of eligible studies ( $n=56$ )

We identified fifty-six eligible studies, described in detail in Table 3. Data collection for the studies included in the review occurred between 2008 and 2020, and 


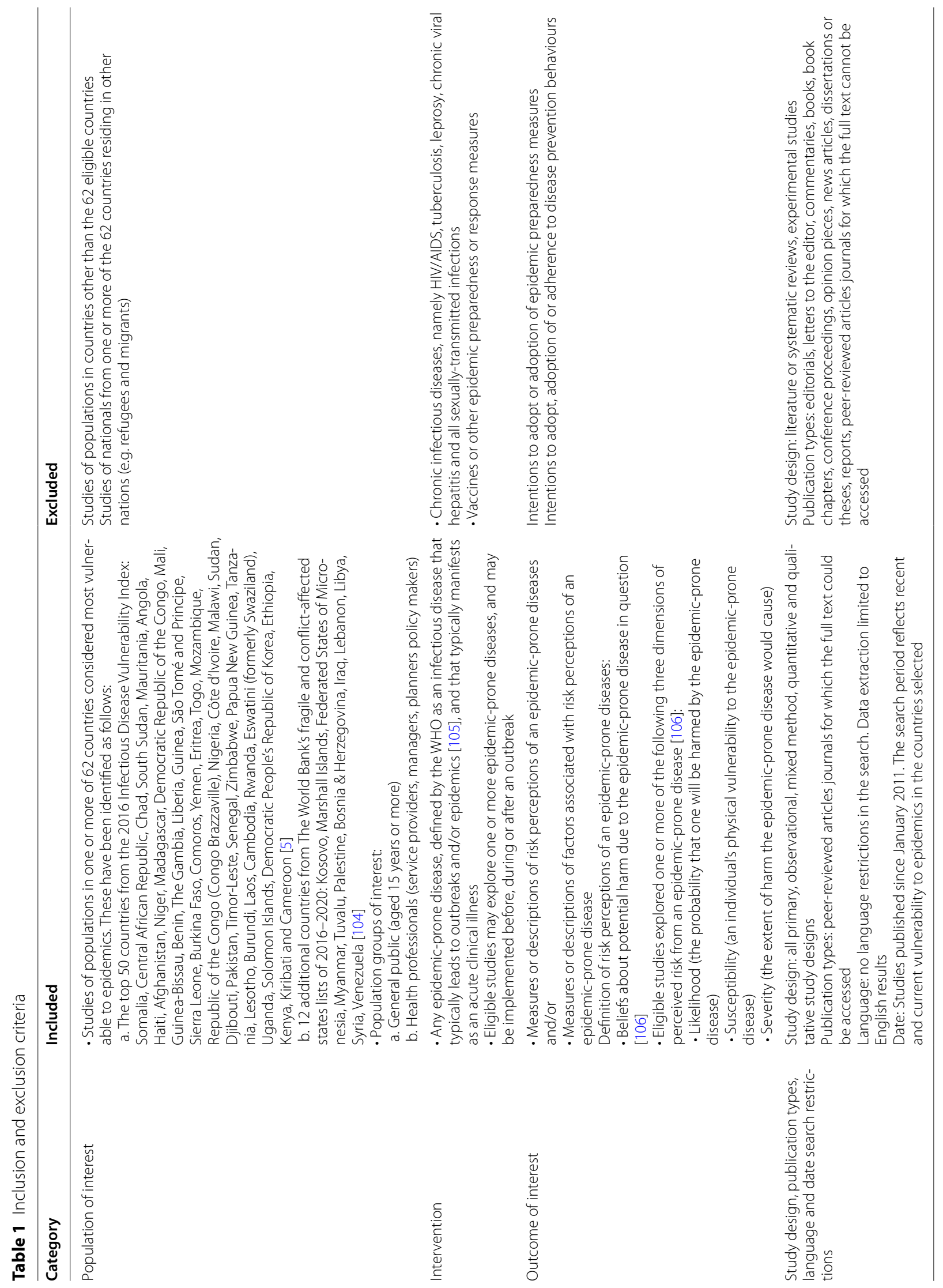


thirty-seven studies collected data during an active epidemic. Fifty-five studies were cross-sectional, forty-five collected quantitative data, six collected qualitative data and five used mixed methods. The majority of studies were on either Ebola virus disease (EVD) $(n=19)$ or coronavirus disease (COVID-19) $(n=18)$. Three studies compared the risk perception of two or more pathogens in the same population [38-40]. Thirty-three studies measured only one of the four dimensions of risk perception; perceived likelihood of infection was the most frequently reported-on dimension. The main features of the eligible studies are summarised in Table 4.

Below, we summarise themes related to risk perception and factors influencing risk perceptions, for the general population and health professionals separately.

\section{Epidemic risk perceptions among the general population $(n=41)$}

Forty-one studies included measurement or description of risk perception of epidemic-prone diseases among non-expert populations. Regardless of countries, diseases under study or whether there was an active outbreak at the time of the study, participants tended to report a high perceived severity of epidemic-prone diseases, generally above the midpoints of severity scales used by researchers [39, 41-52]. In contrast, perceived personal likelihood of contracting an epidemic-prone infection varied across studies, from low [52-56] to moderate [57-61] and high $[42,43,47-49,51,62-64]$. This variation persisted across countries, diseases under study and whether there was an active outbreak at the time of the study. For example, two COVID-19 studies in Ethiopia in 2020 reported contrasting levels of perceived likelihood [54, 62]. However, perceived likelihood of personally contracting infections tended to be lower than perceived severity in studies that measured both aspects of perceived severity [45, 46, 51, 52].

Another theme was a pattern of perceiving risk of epidemic-prone diseases to others as higher than to self, and that the risk to distant individuals or communities is higher than to closer ones. For example, in a study in Sierra Leone, participants perceived the threat of EVD as highest for the country, followed by the district, community then household [50]. Another study of perceived zoonotic infection risks among market vendors also showed a perceived lower risk of infection to self, compared to the rest of the general population [65].

Among groups with a higher risk of exposure to epidemic-prone diseases, perceived likelihood of infections appeared lower than among the general population. For example, among suspected cholera patients, only a quarter thought they were at high risk of contracting cholera again-even where researchers found high levels of water contamination in their households at the time of the study [66]. Similarly, two studies showed that bushmeat hunters and vendors had reduced perceived likelihood of EVD compared to bushmeat consumers [67], and of zoonotic infections compared to vendors selling livestock or vegetables [65].

Participants also perceived some populations groups as more susceptible to risks of epidemic-prone diseases than others. For example, both internally-displaced persons (IDP) and non-displaced host communities perceived IDPs as more vulnerable to dengue fever [52]. Similarly, adult community members perceived pregnant women and children to malaria compared to others in malaria-endemic regions [48].

\section{Information sources and channels}

Respondents who acknowledged the risk of acquiring EVD in the next 6 months during an outbreak were more likely to acquire information from their community (e.g. community leaders, friends and relatives) or new media (e.g. internet, text messages), and accessed three or more information sources. Television, radio, house visits by health workers and government campaigns, and using two or less information sources appeared to have no influence on perceived risk [68]. Two studies showed inconsistent effects of newspapers, brochures and billboards on risk perception $[60,68]$. Previous community experience of disease [55] and exposure to a new and unfamiliar disease [67] were associated with increased risk perception.

\section{Individual factors}

Demographic factors showed inconsistent influences on risk perception across countries and diseases. Education level [54, 60, 62, 65, 68], disease-specific knowledge [44, $54,68,69]$, rural or urban residence [41, 42, 62], marital status [54, 62], income level [54, 62], gender [41, 54, $62,68,69]$ and age $[42,54,62,68,69]$, variably showed positive, negative or no association with epidemic risk perception across different studies. Larger family size [62] and certain occupations $[60,62]$ were associated with increased perceived risk in two studies. By contrast, employment status [54] was not associated with risk perception. While no specific religion was associated with risk perception [41, 62], belief in divine or spiritual protection against harm appeared to reduce perceived EVD risk $[59,67]$.

\section{Disease attributes}

Disease case fatality ratios and infection risks seemed to influence risk perception, indicating the role of numeracy 


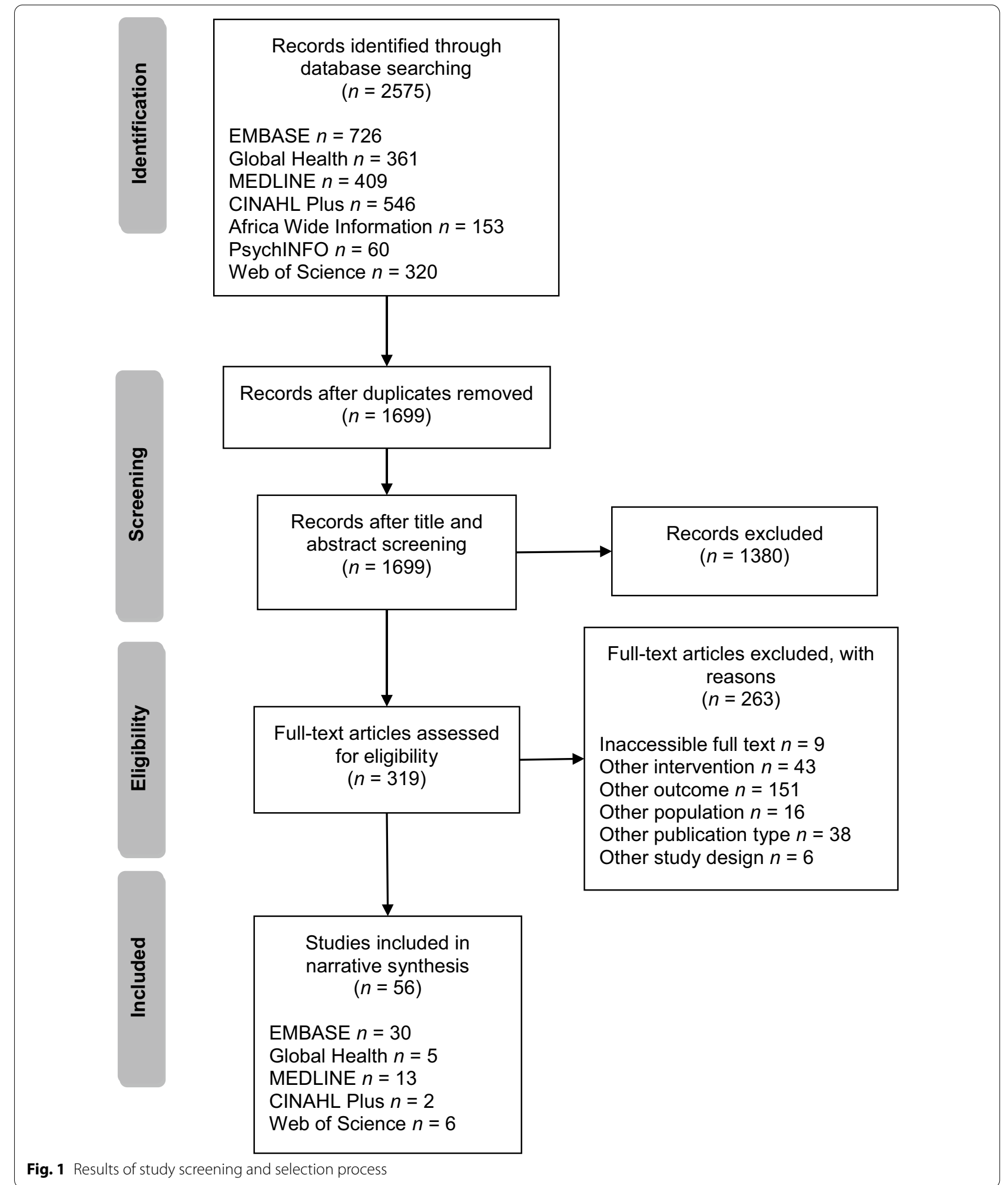

skills [39]. The phase of an outbreak also seemed influential: an ongoing outbreak of typhoid fever was associated with a grave concern that cases would continue to increase [39], while the likelihood of acknowledging the risk of acquiring infection decreased as an EVD outbreak progressed [68]. Some disease attributes were associated 
Table 2 Categorisation of eligible studies for analysis

\begin{tabular}{|c|c|}
\hline Study population groups (A) & Risk perception dimension groups (B) \\
\hline $\begin{array}{l}\text { Group A1: all studies of risk perceptions among the general population } \\
\text { Group A2: all studies of risk perceptions among health professionals } \\
\text { Note: studies which include both public and health professional populations } \\
\text { are included in both groups }\end{array}$ & $\begin{array}{l}\text { Group B1: all studies exploring perceived likelihood as a dimension of risk } \\
\text { perception } \\
\text { Group B2: all studies exploring perceived susceptibility or vulnerability as a } \\
\text { dimension of risk perception } \\
\text { Group B3: all studies exploring perceived severity as a dimension of risk } \\
\text { perception } \\
\text { Note: studies that explore more than one definition of risk perception were } \\
\text { included in more than one group }\end{array}$ \\
\hline
\end{tabular}

with an increased risk perception among participants, specifically diseases perceived as hard to control through community infection control measures [38], unfamiliar diseases [67], and severe diseases [39, 67]. Participants cited multiple features of evident disease severity, such as rapid spread, unpredictable nature, severe or debilitating symptoms, ineffectiveness of traditional or biomedical treatments and the profound economic consequences of a debilitating illness [39, 67].

\section{Health protective behaviours}

Three studies explored the association between risk perception and a person's belief in their ability to protect themselves from EVD, and concluded that a higher selfefficacy is associated with lower perceived risk and vice versa [58-60]. Another study found that vaccination against EVD lowered perceived likelihood and alleviated worry [70]. However, the relationship between risk perception and protective behaviours against EVD was not consistent; for example, one study reported that while handwashing had a positive association with risk perception, avoiding burials was negatively associated with risk perception, and avoiding physical contact with a suspected EVD case not associated with risk perception [68].

\section{The sociocultural context}

Among vendors, familiarity with, knowledge of and preference of a vendor's own products, was associated with a reduced perceived risk of zoonotic infections. In one study of perceived zoonotic infection risks among market vendors in Lao, vegetable vendors reported that their products were "organic", "healthy" and "natural", and livestock meat vendors mentioned that their meat was mainly sourced from slaughterhouses with robust veterinary control [65]. For some bushmeat vendors, not being involved in the hunting and killing of wild animals seemed to be perceived as reducing their risk of zoonotic infections [65]. Another study amongst bushmeat handlers in Nigeria reported a low perceived risk of EVD and questioned the plausibility that well-established traditional uses of bushmeat, such as diet, spiritual fortification and treatment of disease conditions, could be risky [67].

In a multi-country study of the sociocultural features of cholera, the authors observed that in Kenya, respondents perceived women and children as more vulnerable to cholera compared to the general population, and suggested that this may be due to greater cultural sensitivity to vulnerability amongst the study participants, and a tendency to generalize the vulnerability of alreadyvulnerable population groups to include susceptibility to disease [41].

Table 5 summarizes the factors reported by eligible studies and their influence of epidemic risk perceptions among the general population, by element of the SARF.

\section{Epidemic risk perceptions among health professionals $(n=19)$}

Studies reporting on health professionals' epidemic risk perceptions focused on how they perceived their own risk rather than the risk to communities they served. All studies but one concerned epidemic-prone infections that can readily be acquired in a healthcare setting: COVID-19, EVD, Marburg virus and pandemic influenza A (H1N1). Eighteen studies included clinical staff, six included non-clinical health facility staff, and three studies included community-based health workers. One study solely included medical students [71].

Health professionals generally reported high perceived likelihood and susceptibility to infections [72-77]. In three studies, however, only about a third considered themselves to be at risk [78-80]. All three studies were conducted during an active outbreak in Nigeria: two related to EVD, and one related to H1N1. Health professionals generally reported a high perceived severity of epidemic-prone diseases [71, 77, 81, 82], including high perceived disease severity should they acquire the infection themselves [72, 75].

When comparing clinical to non-clinical staff, the results of perceived risks were inconclusive. One study reported that clinical staff had higher perceived risk than non-clinical staff [74], while another study reported no significant difference in fear ratings of doctors, nurses, 


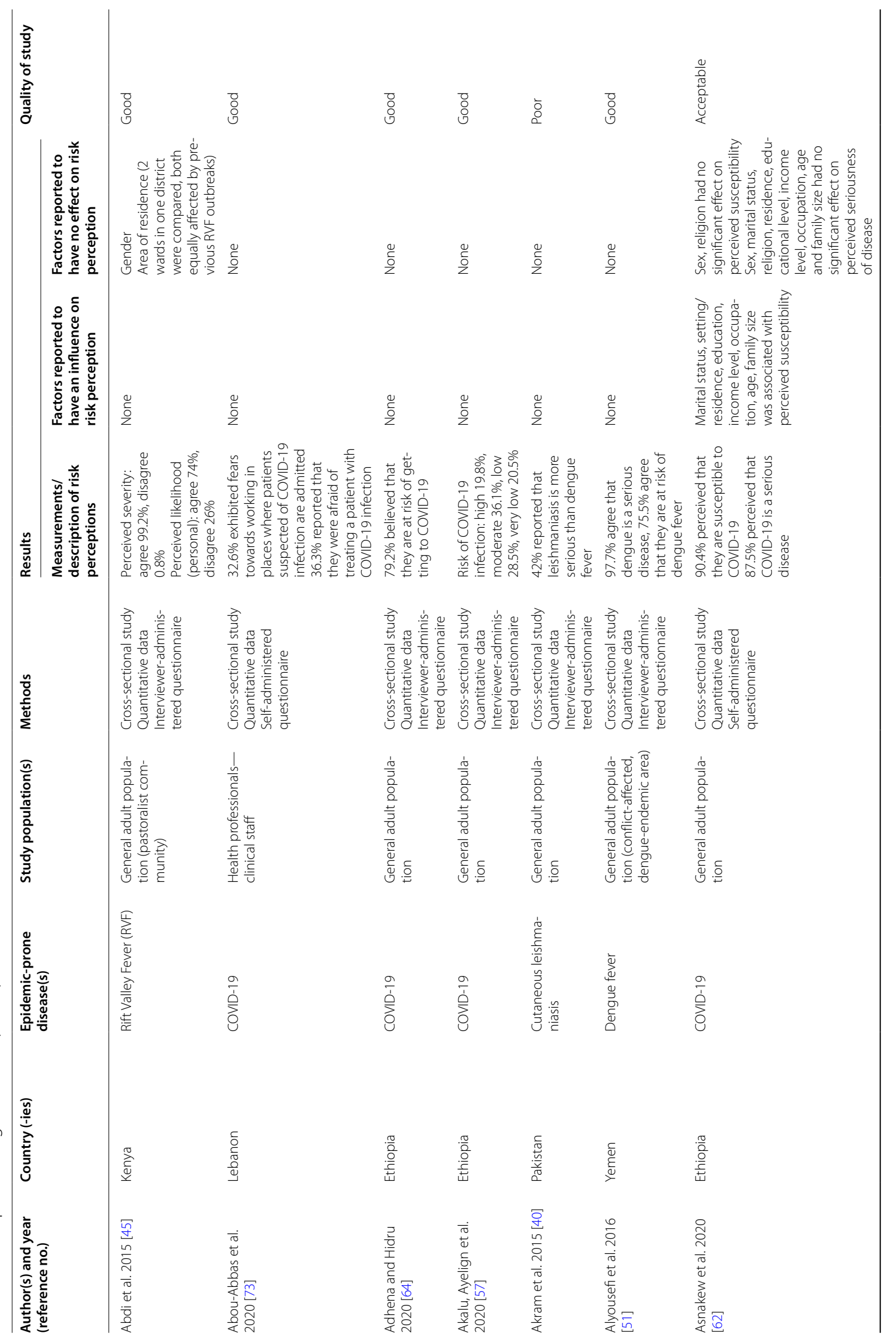




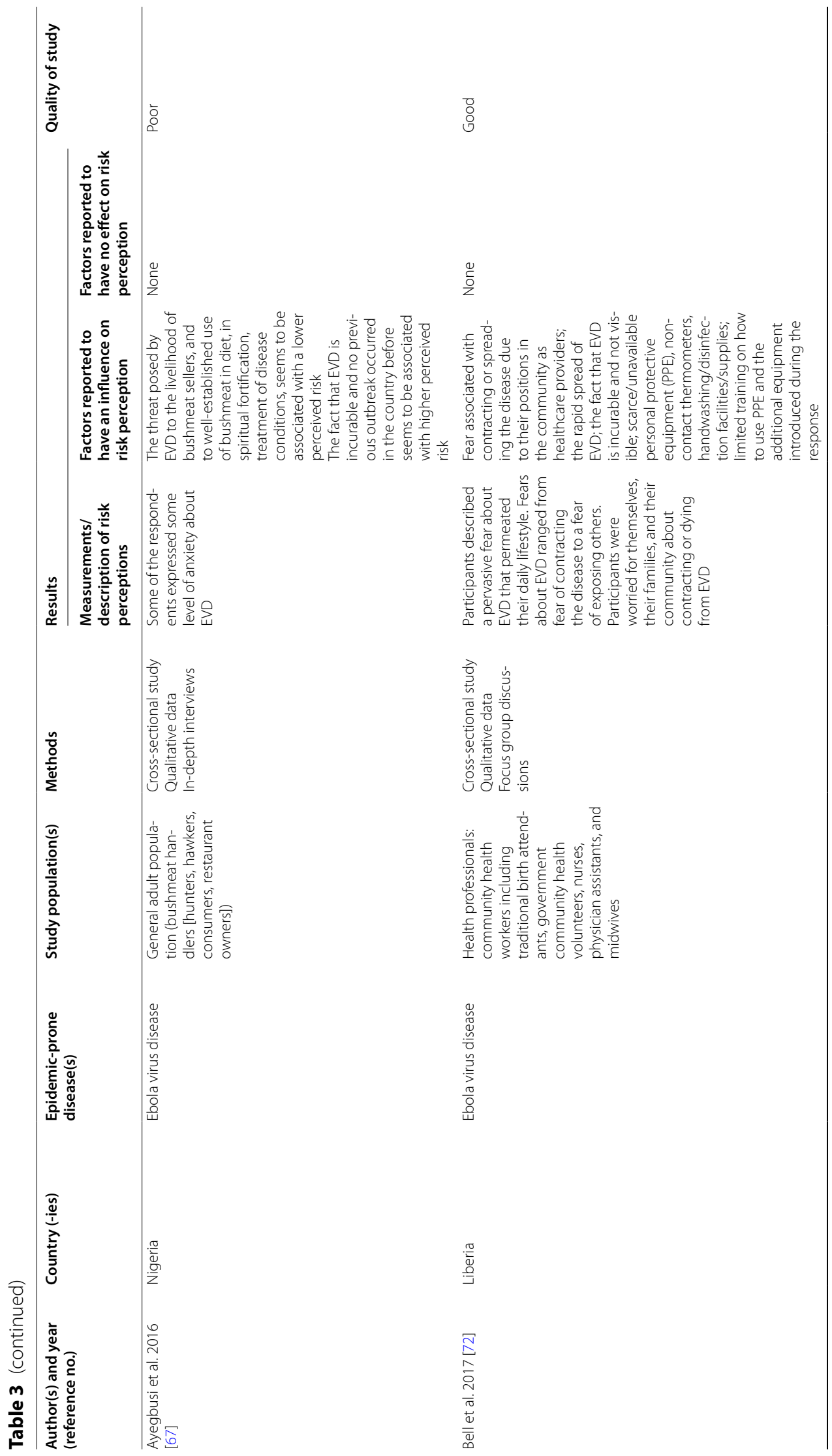




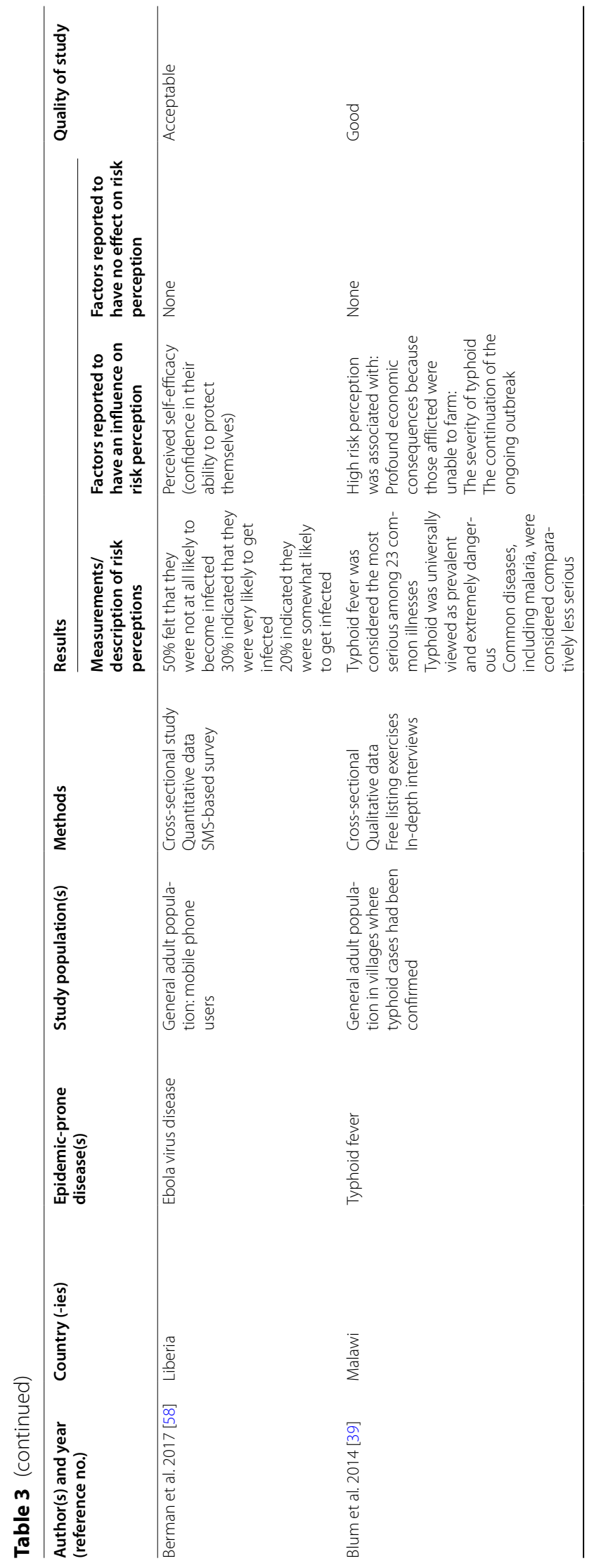




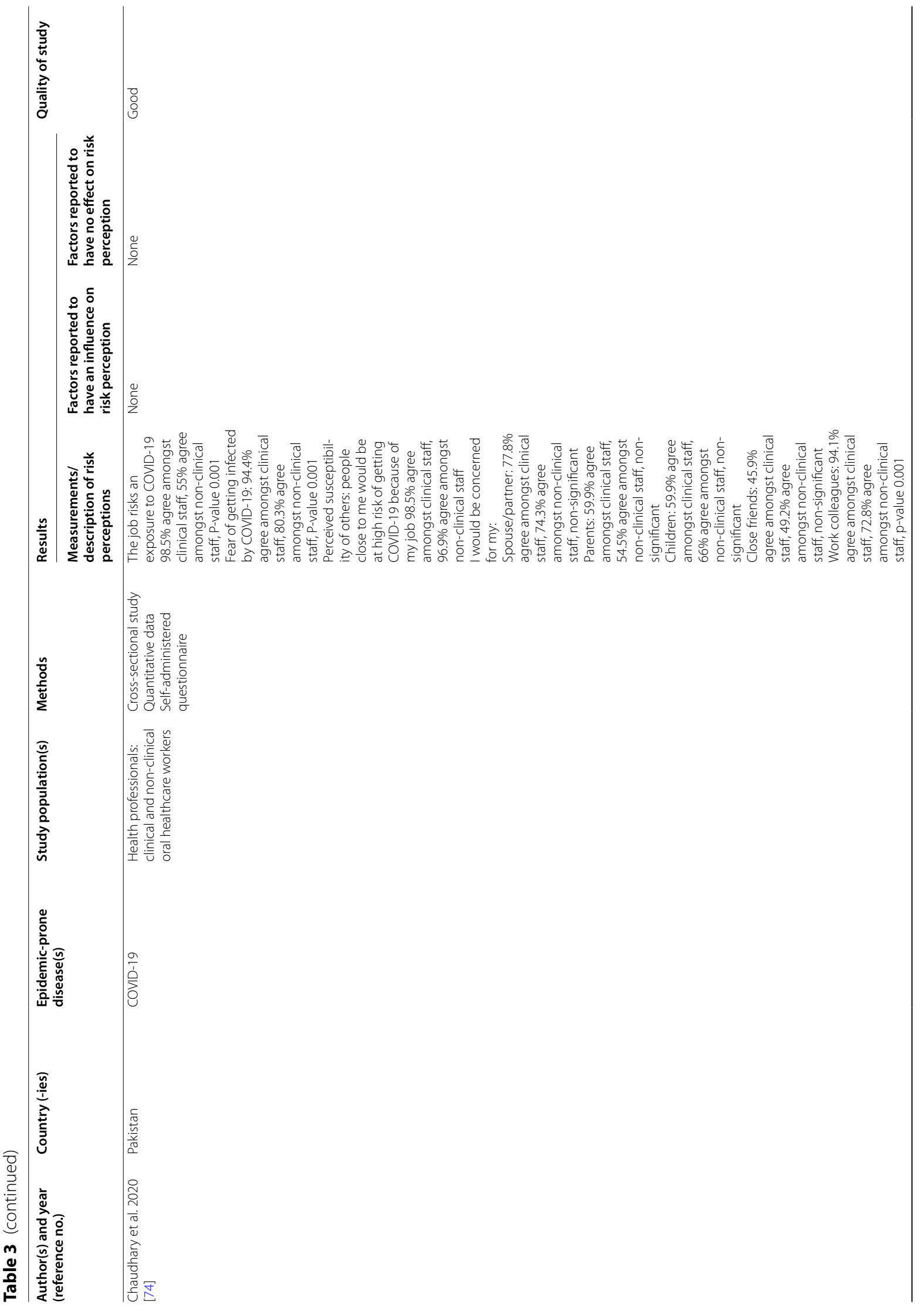




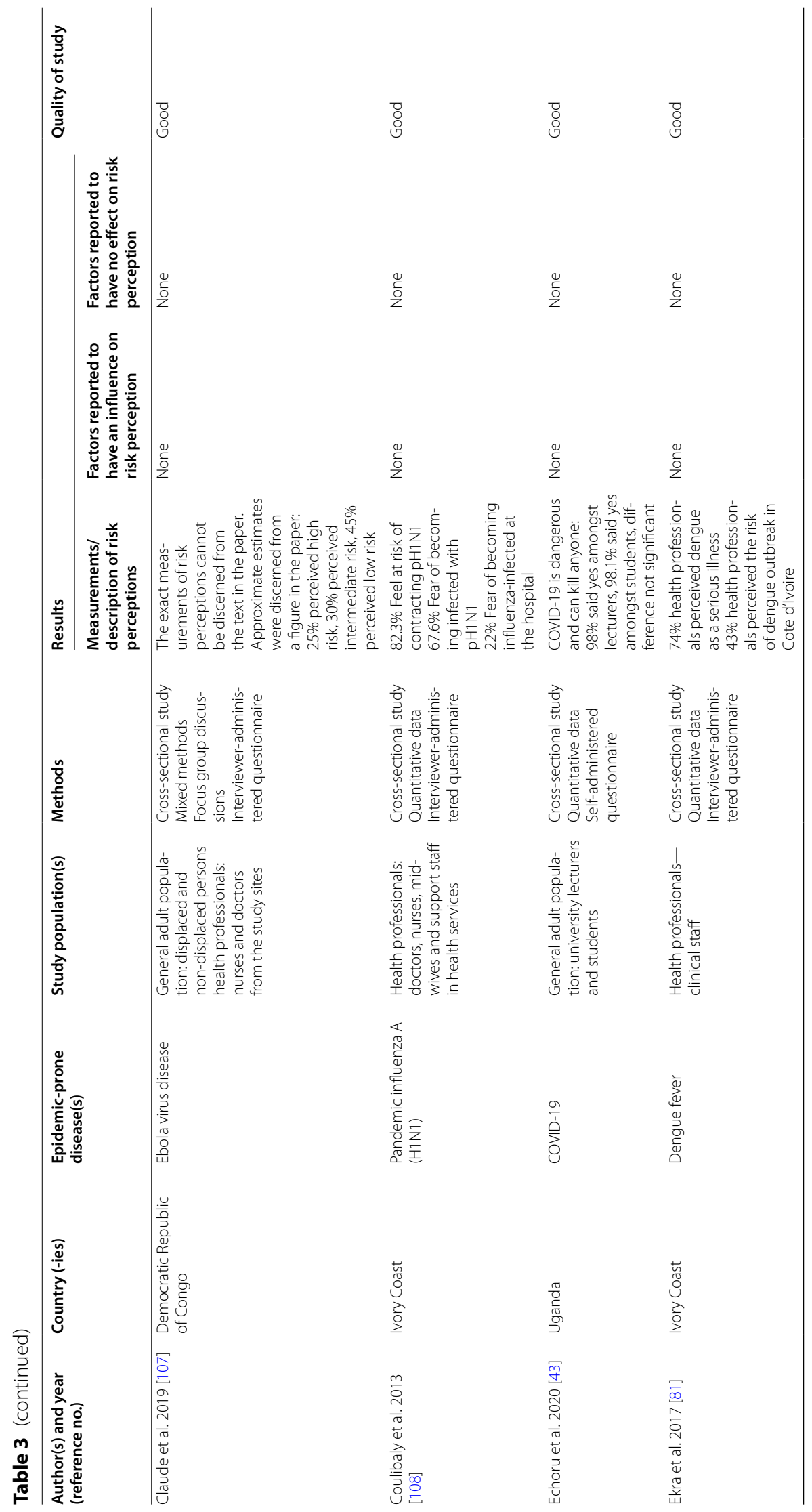




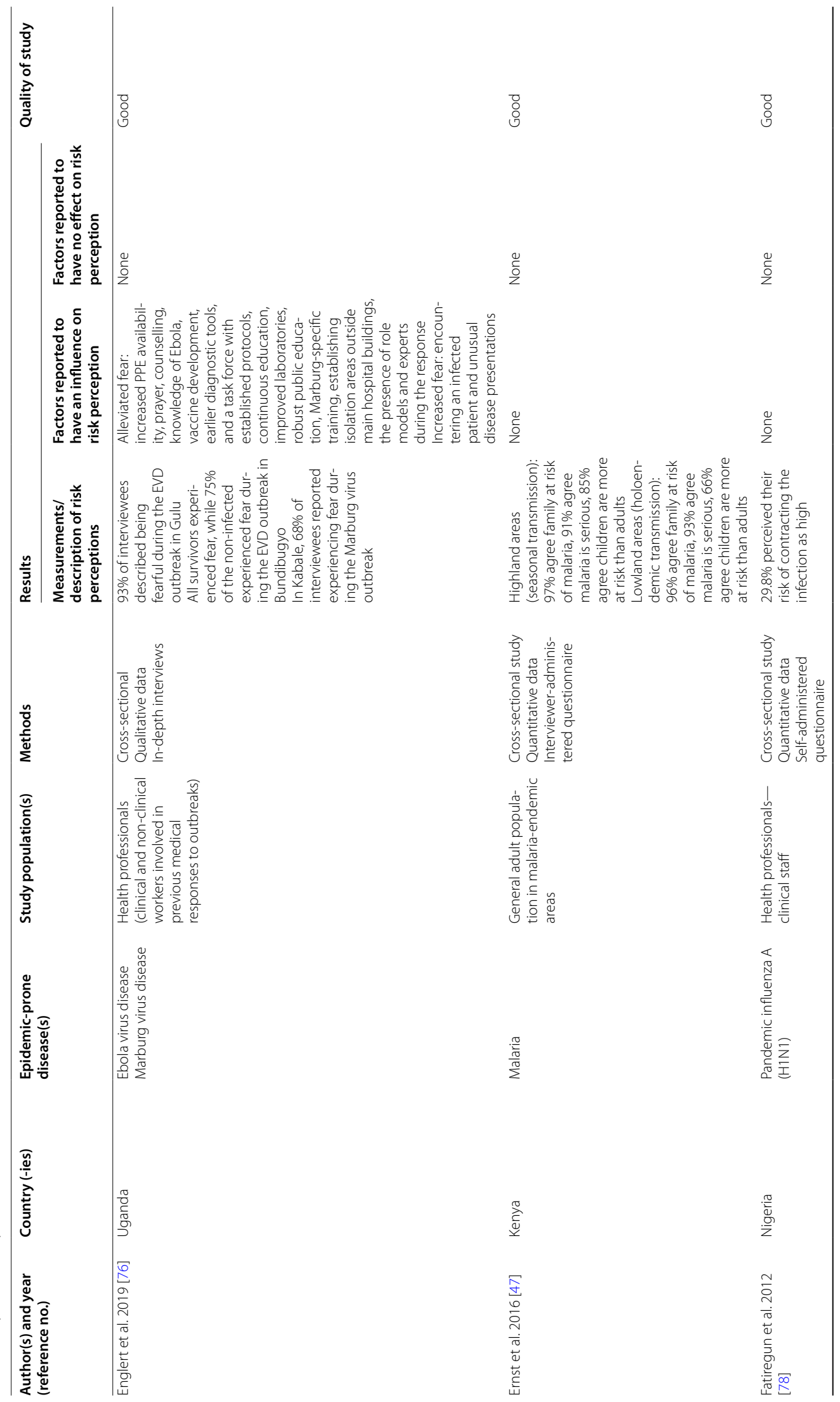




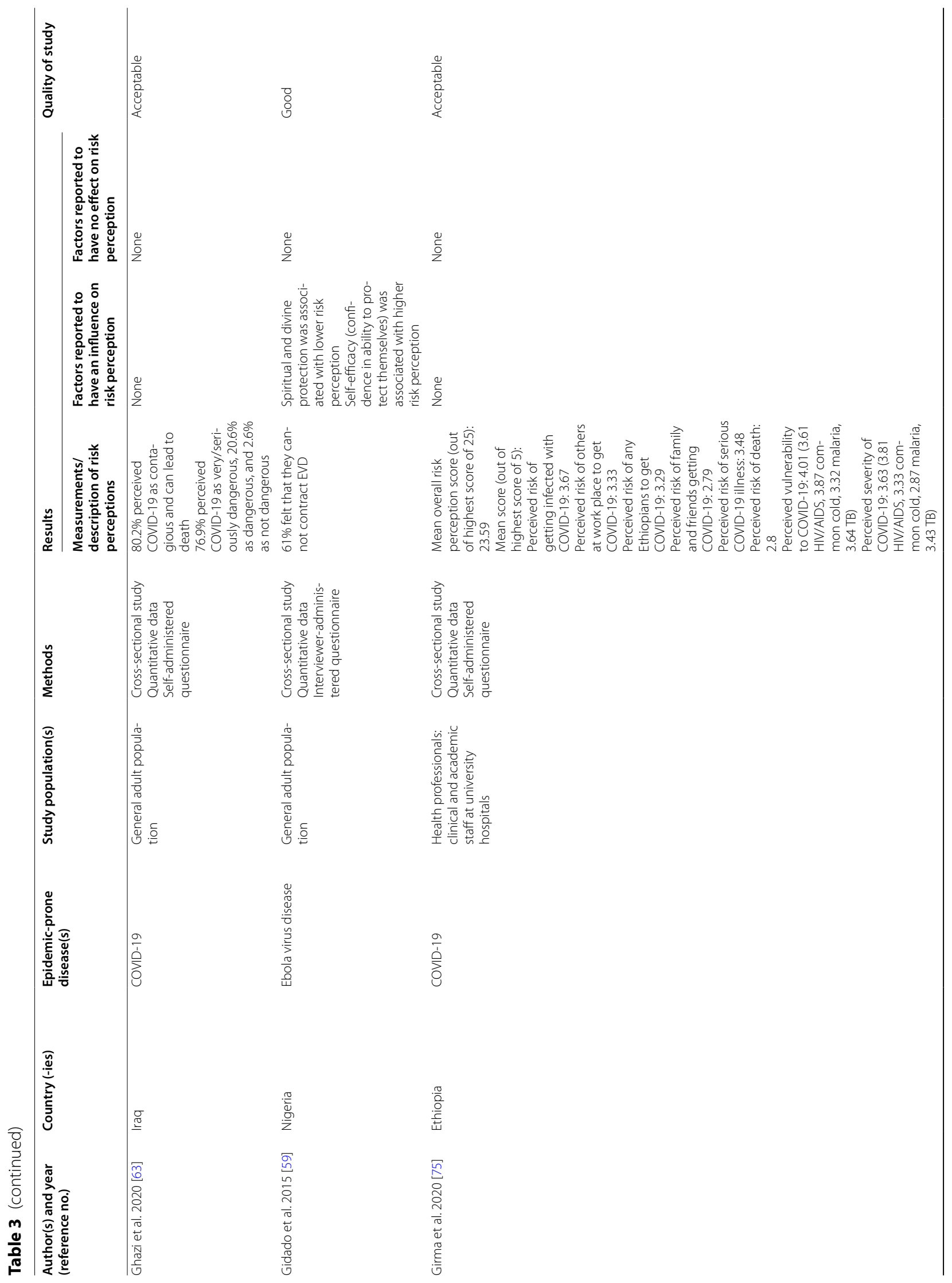




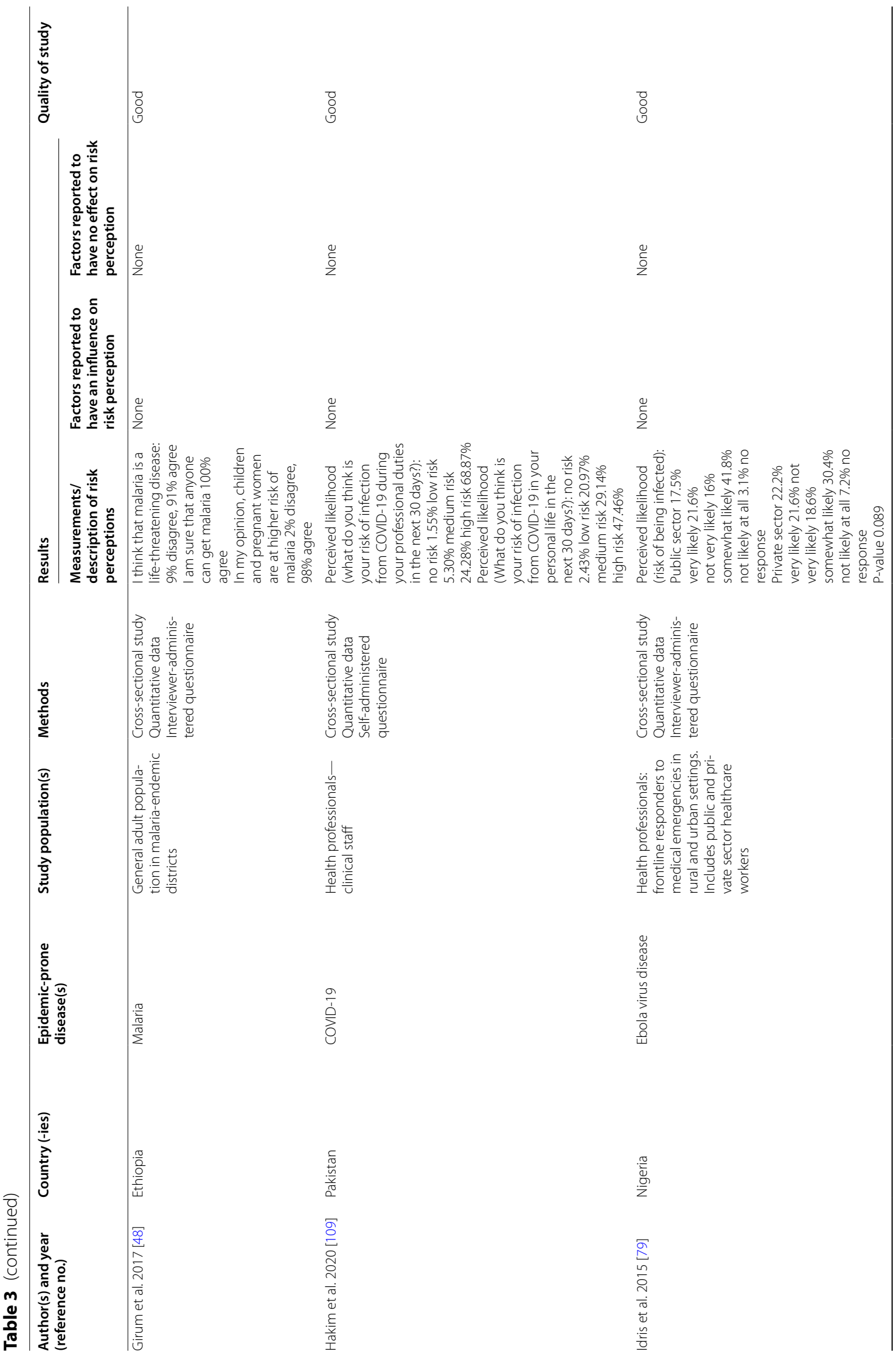




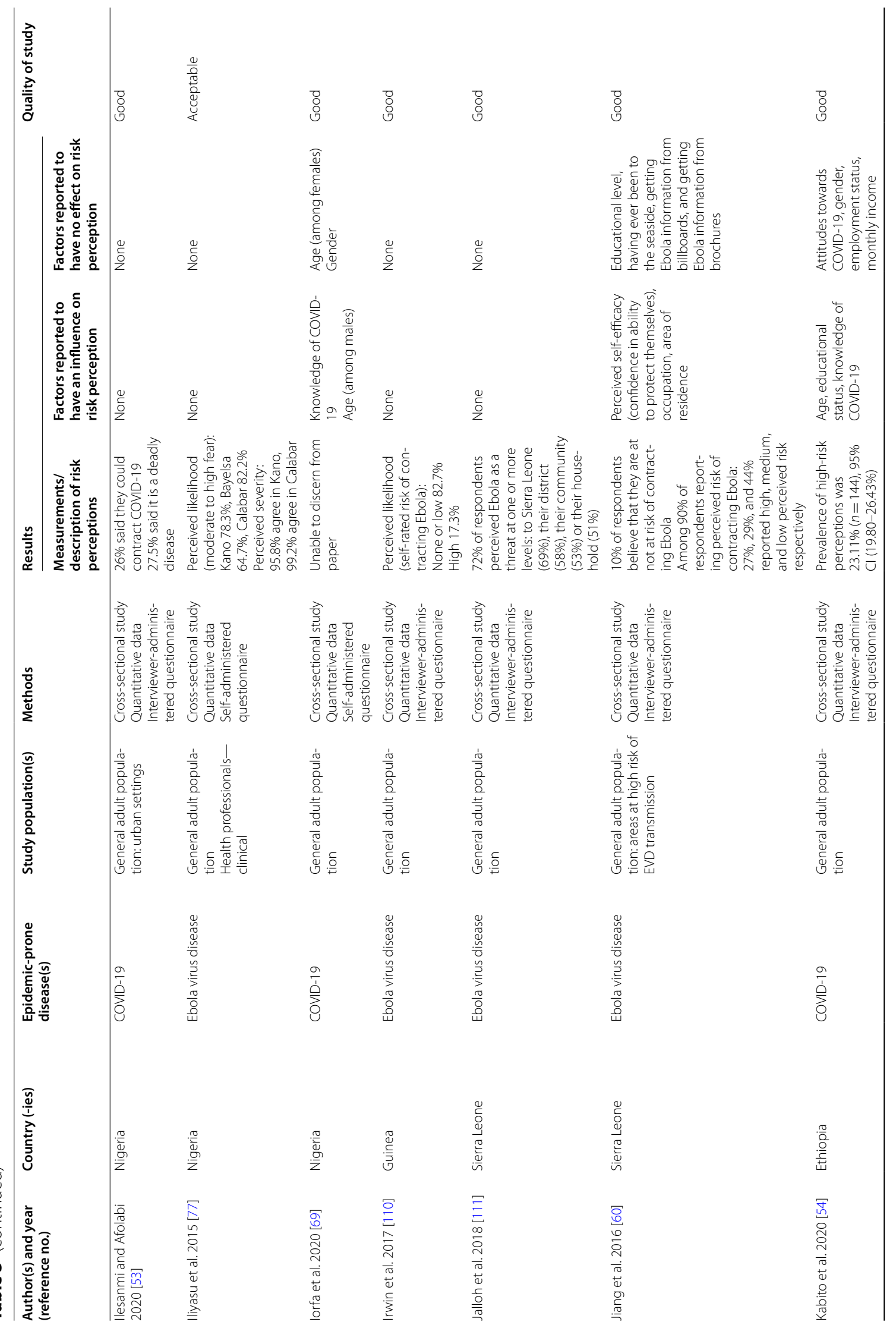




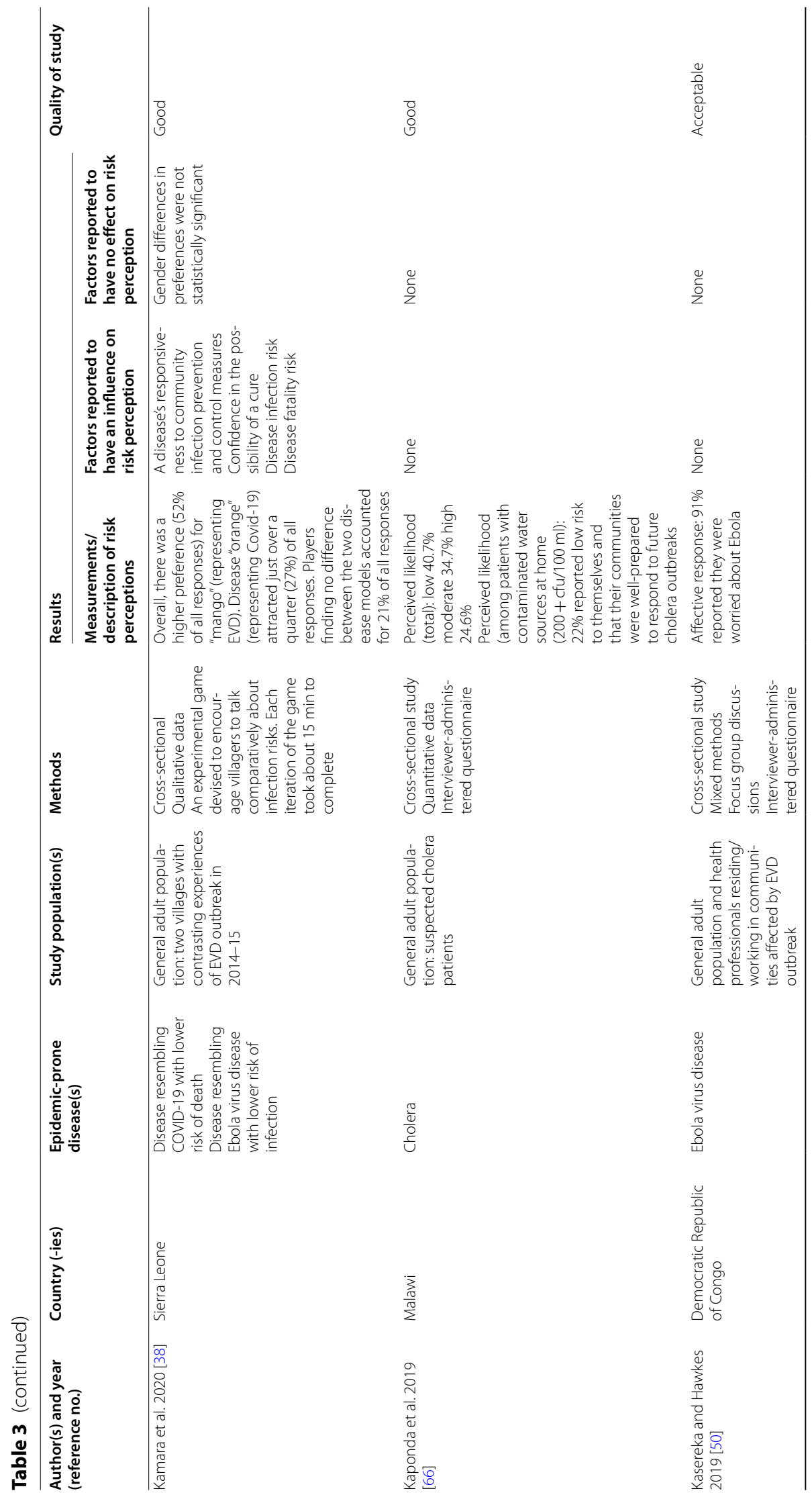




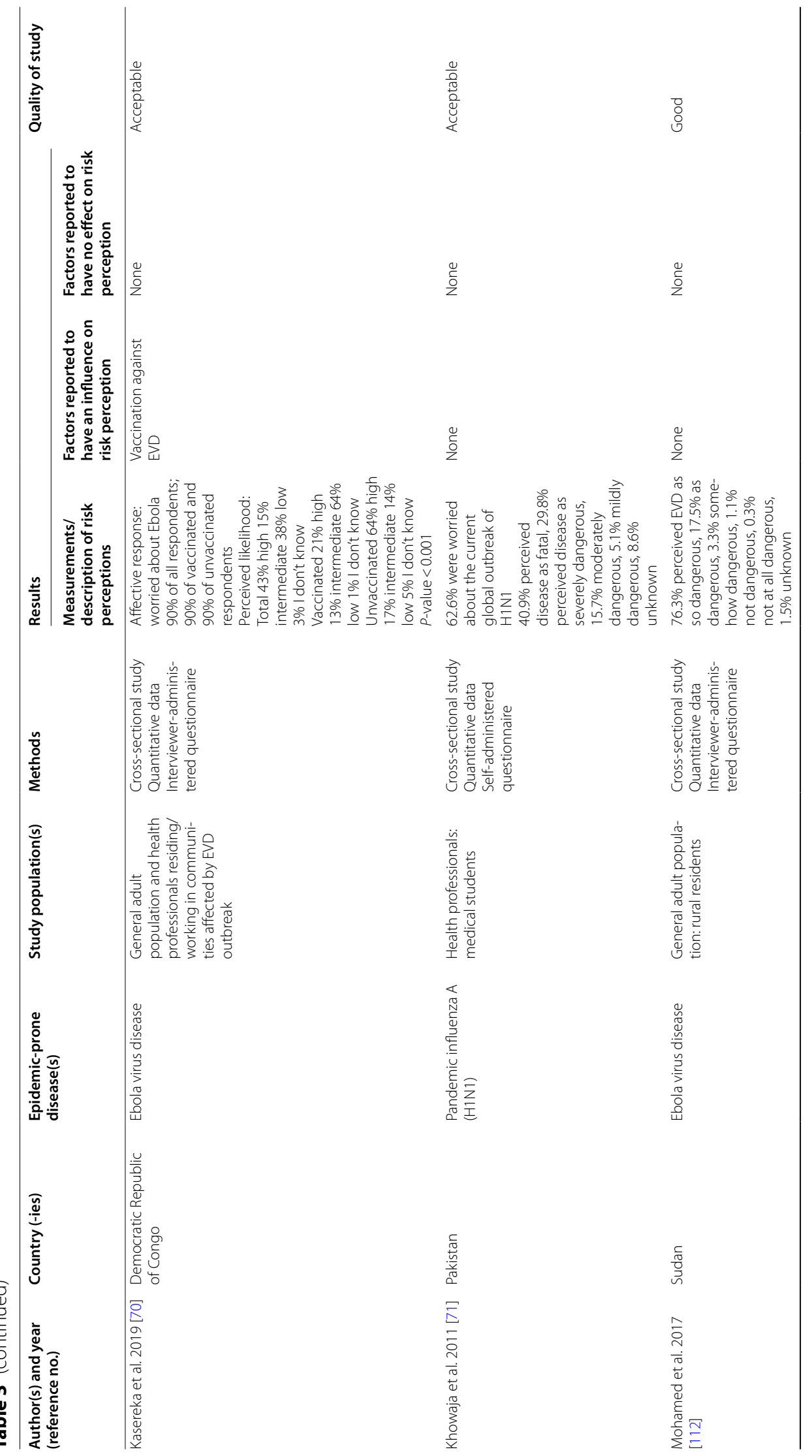




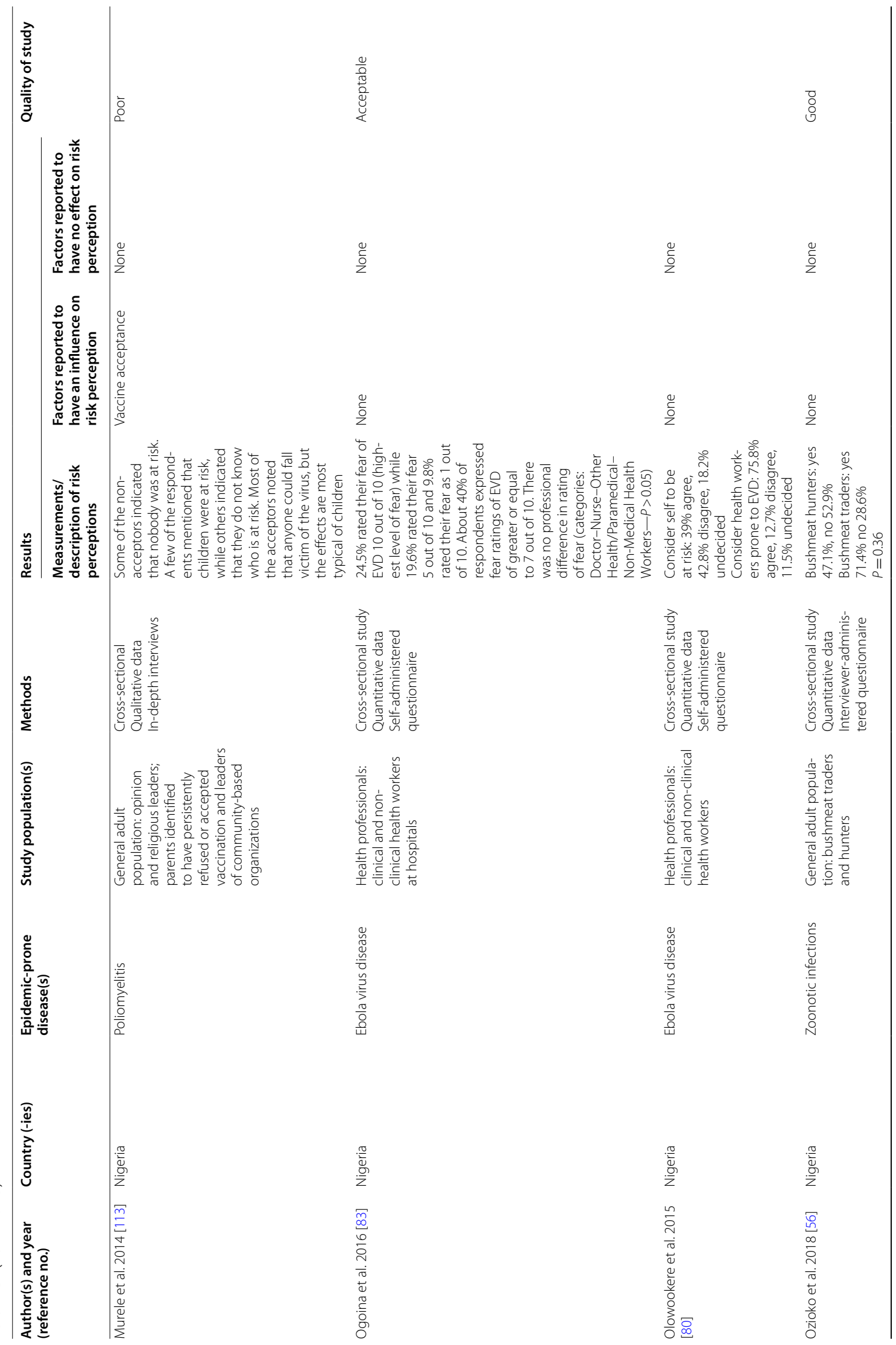




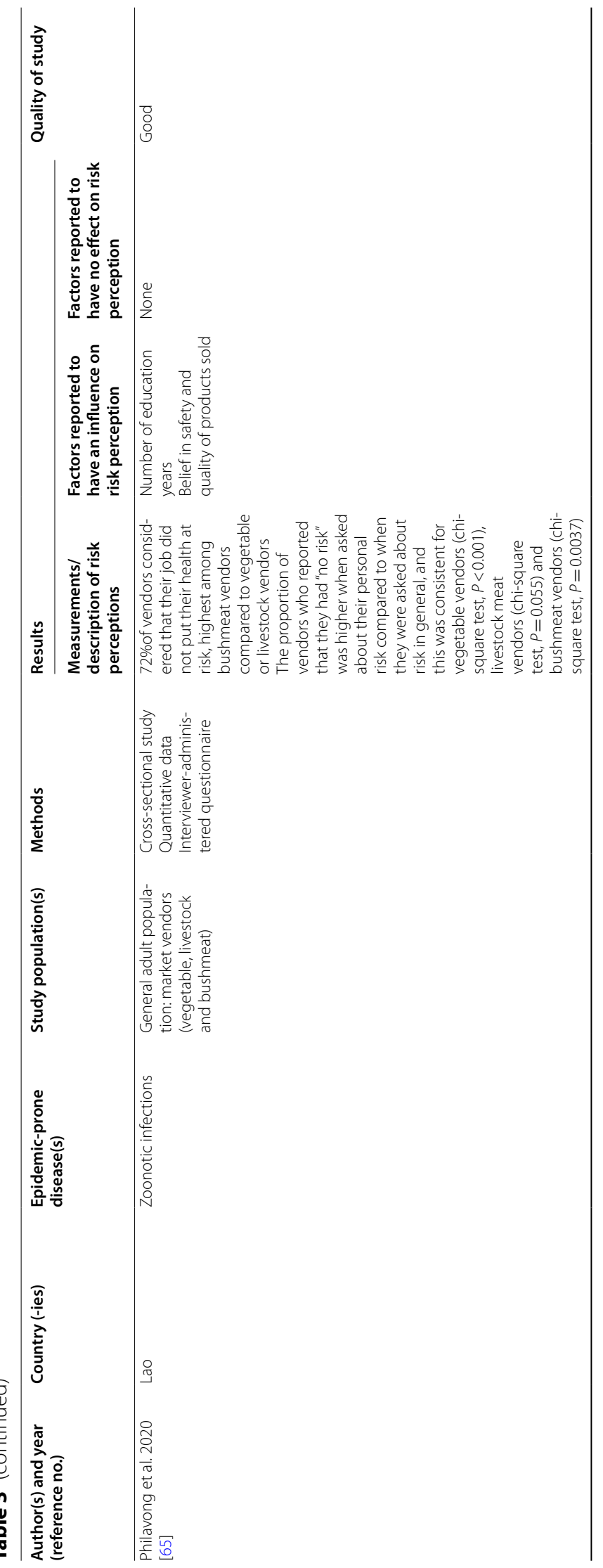




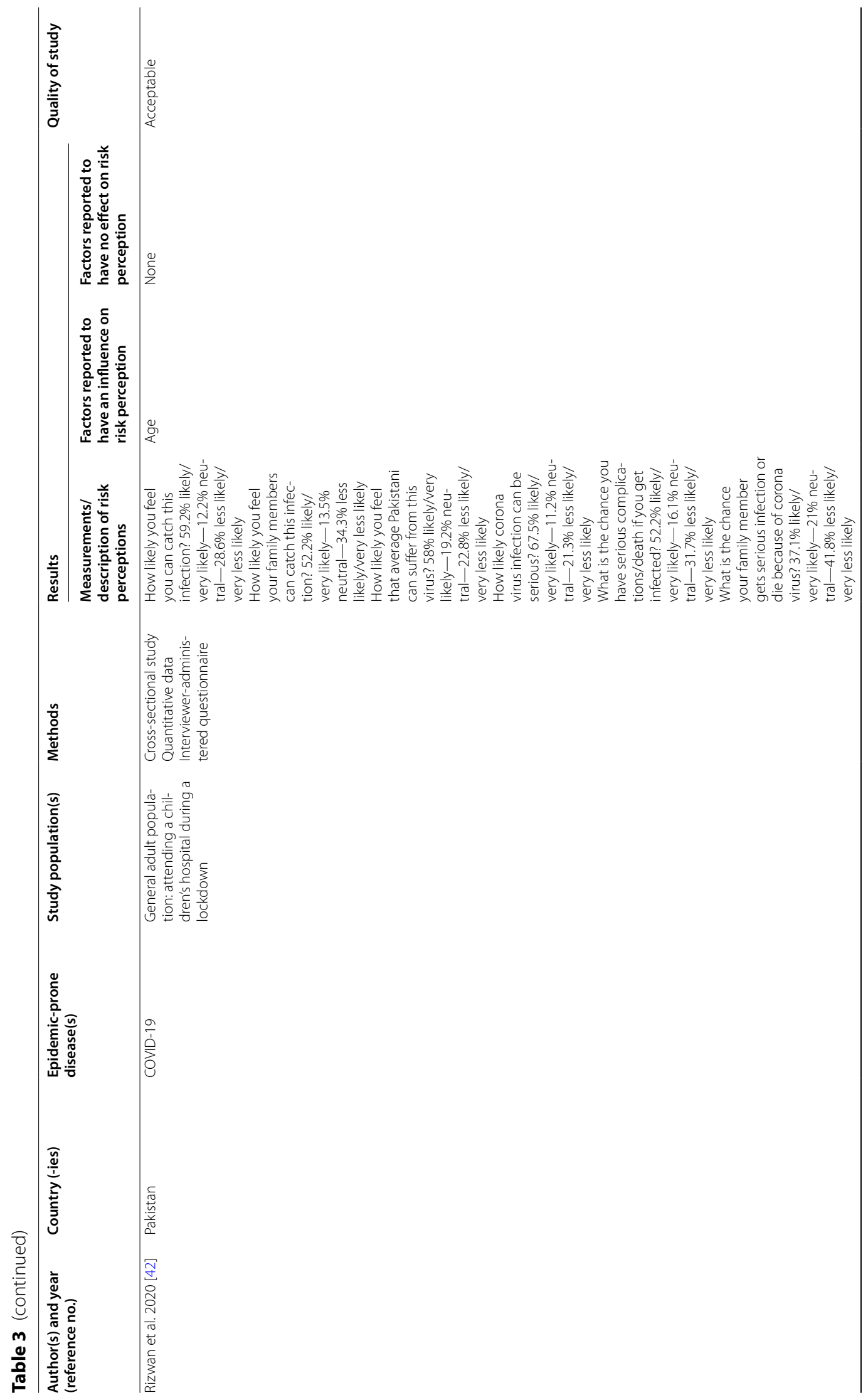




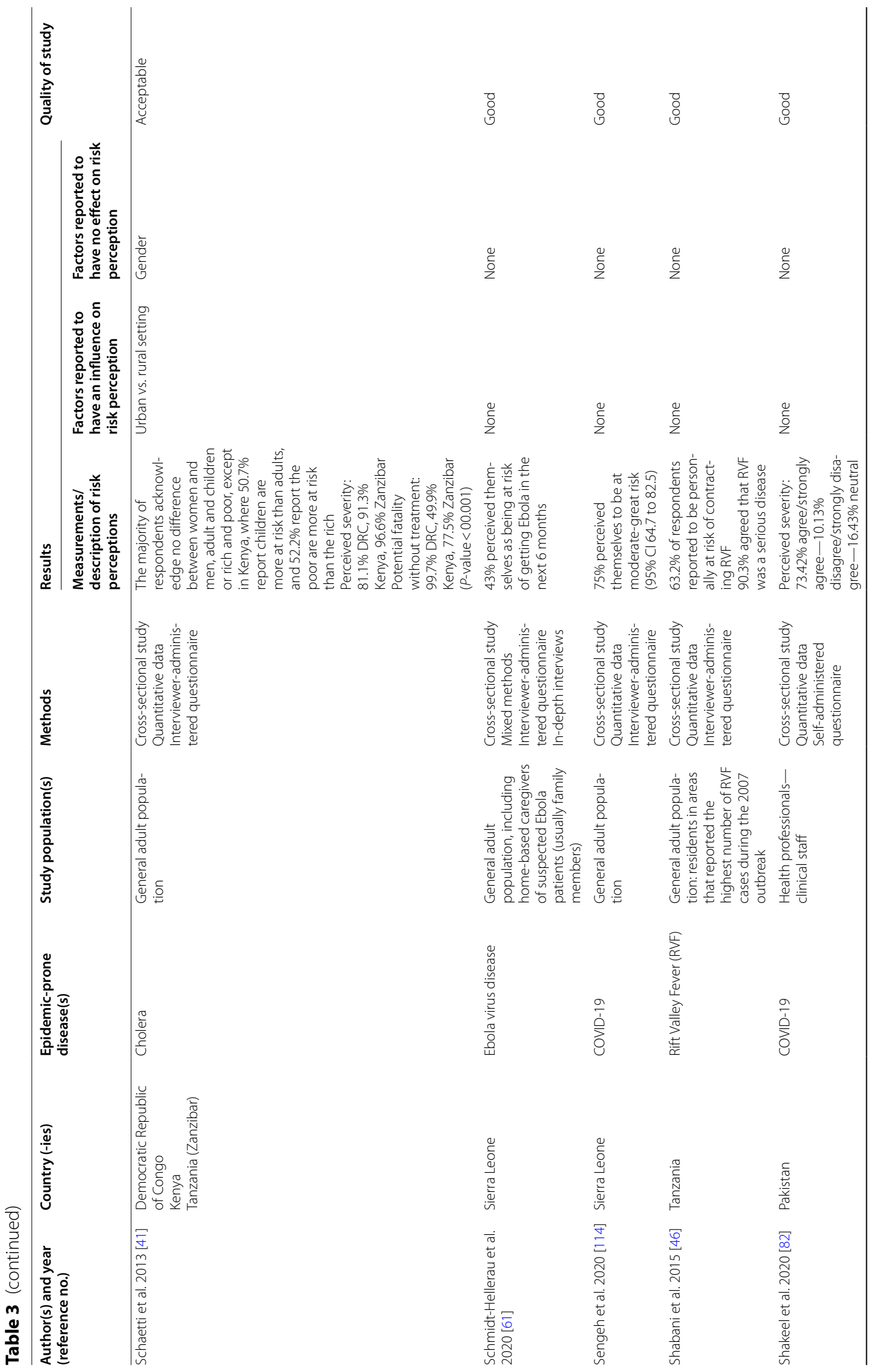




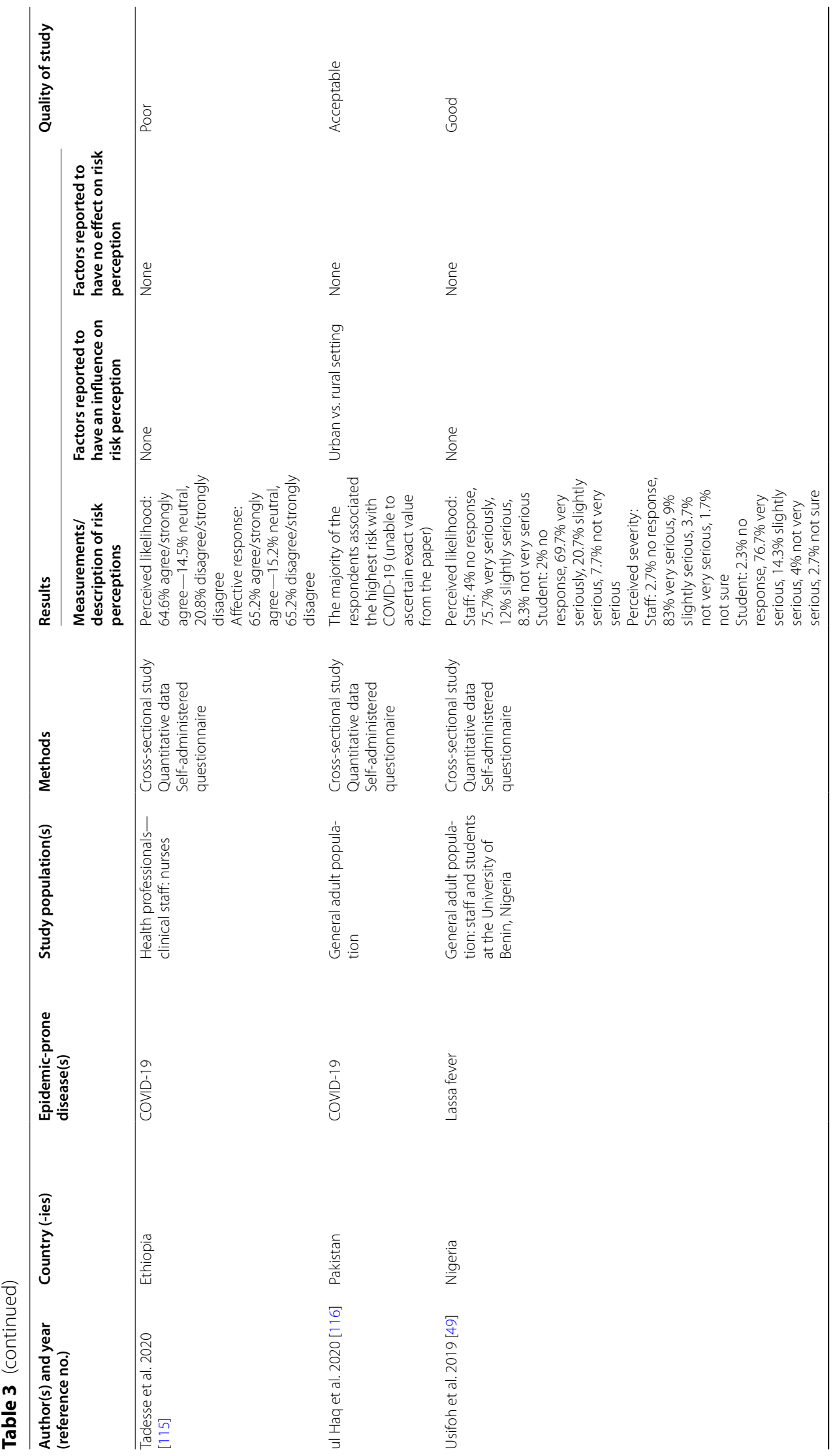




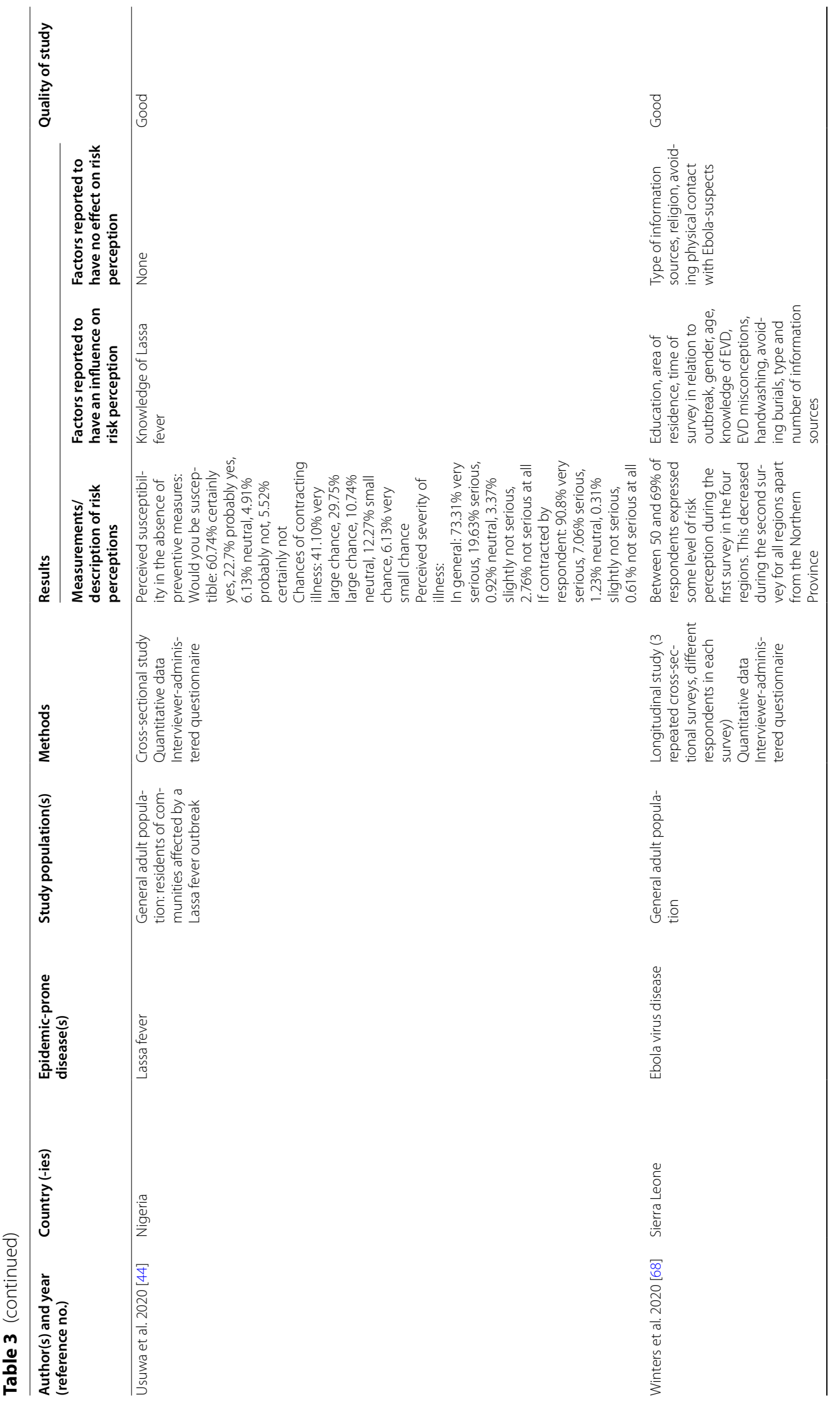




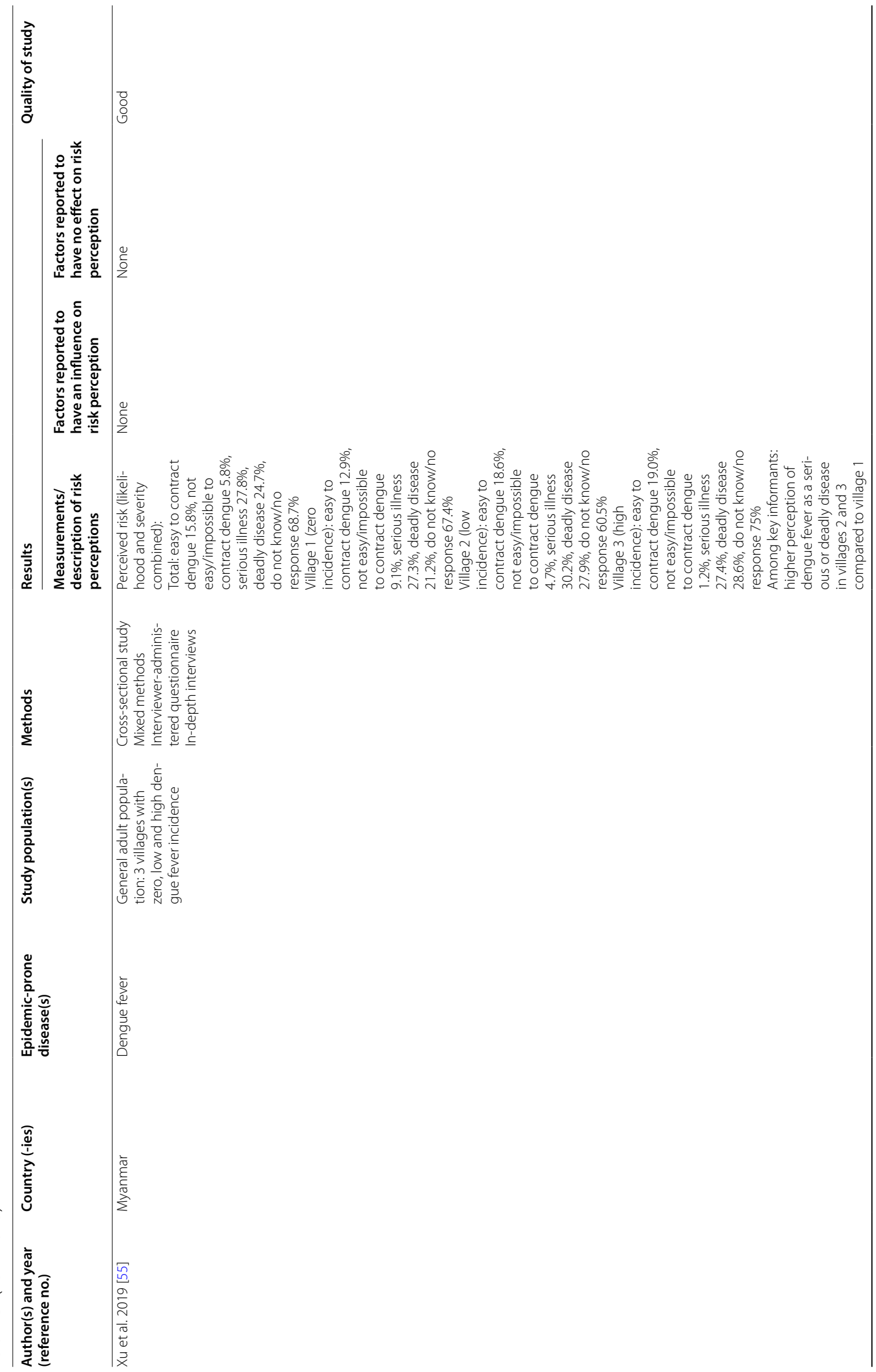




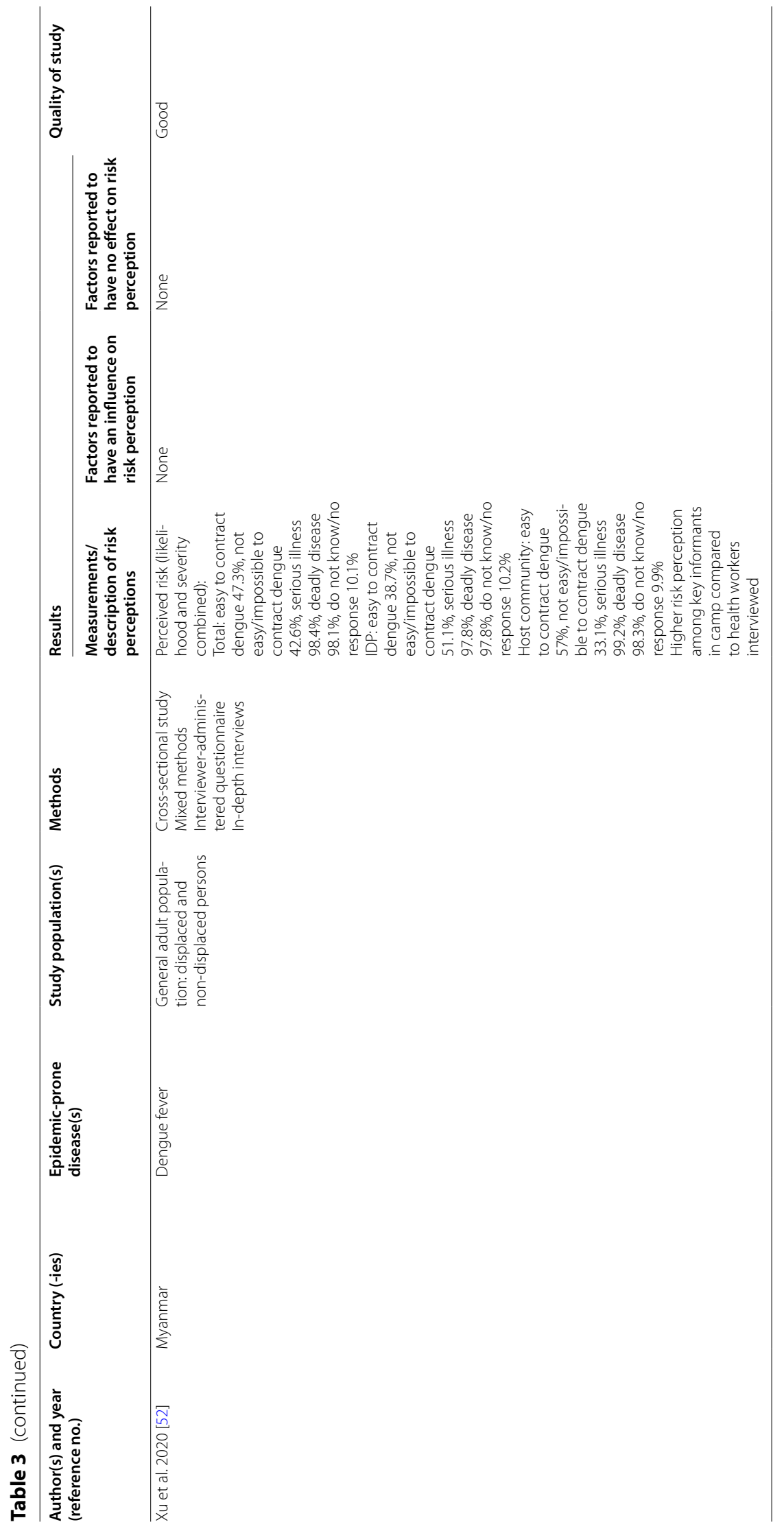


Table 4 Main features of eligible studies

\begin{tabular}{|c|c|}
\hline Characteristic & $\begin{array}{l}\text { Number } \\
\text { of studies }\end{array}$ \\
\hline \multicolumn{2}{|l|}{ Country } \\
\hline Democratic Republic of Congo & $4^{a}$ \\
\hline Ethiopia & 5 \\
\hline Guinea & 1 \\
\hline Iraq & 1 \\
\hline Ivory Coast & 2 \\
\hline Kenya & $3^{\mathrm{a}}$ \\
\hline Lao & 1 \\
\hline Lebanon & 1 \\
\hline Liberia & 2 \\
\hline Malawi & 2 \\
\hline Myanmar & 2 \\
\hline Nigeria & 13 \\
\hline Pakistan & 7 \\
\hline Sierra Leone & 6 \\
\hline Sudan & 1 \\
\hline Tanzania & $2^{a}$ \\
\hline Uganda & 2 \\
\hline Yemen & 1 \\
\hline \multicolumn{2}{|l|}{ Epidemic-prone disease } \\
\hline Ebola virus disease & $19^{b}$ \\
\hline COVID-19 & $18^{\mathrm{b}}$ \\
\hline Dengue fever & $4^{b}$ \\
\hline Pandemic influenza A (H1N1) & 3 \\
\hline Cholera & 2 \\
\hline Lassa fever & 2 \\
\hline Malaria & 2 \\
\hline Rift valley fever & 2 \\
\hline Zoonotic infections & 2 \\
\hline Cutaneous leishmaniasis & $1^{\mathrm{b}}$ \\
\hline Marburg virus disease & 1 \\
\hline Poliomyelitis & 1 \\
\hline Typhoid fever & $1^{\sim}$ \\
\hline \multicolumn{2}{|l|}{ Active epidemic during data collection? } \\
\hline Yes & 19 \\
\hline No & 37 \\
\hline \multicolumn{2}{|l|}{ Type of study population } \\
\hline General population ( 15 years or older) & 40 \\
\hline General population: cases with disease under study & 1 \\
\hline Clinical health professionals & 10 \\
\hline Other health professionals & 9 \\
\hline \multicolumn{2}{|l|}{ Data collection methods } \\
\hline Self-administered questionnaire (in-person or online) & 17 \\
\hline Interviewer administered questionnaire & 32 \\
\hline Focus group discussion & 2 \\
\hline Semi-structured interviews & 7 \\
\hline Free listing & 1 \\
\hline Experimental fame & 1 \\
\hline SMS-based survey & 1 \\
\hline
\end{tabular}

Table 4 (continued)

\begin{tabular}{|c|c|}
\hline Characteristic & $\begin{array}{l}\text { Number } \\
\text { of studies }\end{array}$ \\
\hline \multicolumn{2}{|l|}{ Number of dimensions of risk perception reported on } \\
\hline One & 33 \\
\hline Two & 36 \\
\hline Three & 3 \\
\hline \multicolumn{2}{|l|}{ Dimensions of risk perception reported on } \\
\hline Perceived likelihood & 36 \\
\hline Perceived severity & 27 \\
\hline Perceived susceptibility & 8 \\
\hline Affective risk perception & 14 \\
\hline \multicolumn{2}{|l|}{ Conceptual framework used } \\
\hline No framework & 36 \\
\hline Knowledge, attitudes and practices (kap) & 10 \\
\hline Health belief model & 3 \\
\hline Explanatory model interview catalogue & 1 \\
\hline Moderated mediation model & 1 \\
\hline Ideation metatheory & 1 \\
\hline Social process theory & 1 \\
\hline Weberian social action theory & 1 \\
\hline Original framework developed by authors & 1 \\
\hline \multicolumn{2}{|l|}{ Method for measuring/assessing risk perception } \\
\hline Likert- or Likert-type scale & 34 \\
\hline Dichotomous question (yes/no; agree/disagree) & 11 \\
\hline Open-ended question & 3 \\
\hline Comparison of two diseases & 2 \\
\hline Ranking of diseases & 1 \\
\hline Comparison of vulnerability of two population groups & 1 \\
\hline $\begin{array}{l}\text { Score against pre-determined 'correct' risk perception } \\
\text { defined by author }\end{array}$ & 1 \\
\hline Unable to ascertain & 6 \\
\hline
\end{tabular}

Note that totals may exceed the number of eligible studies $(n=56)$ as some studies explored more than one category

${ }^{\text {a }}$ Of which one is multi-country

${ }^{\mathrm{b}}$ Includes comparison with other pathogens within a study

paramedical staff and non-clinical workers [83]. Similarly, the review findings were inconclusive with regards to whether health workers rated the risk to themselves as higher or lower than that of other health workers $[75,80]$.

\section{Information sources and channels}

Two studies reported that acquiring disease-specific knowledge, for example through training, alleviated fear among health workers and reduced their perceived vulnerability to EVD infection [72, 76].

\section{Disease attributes}

Health professionals reported disease attributes that increased their fear, specifically unusual clinical 
Table 5 Factors reported and their influence on epidemic risk perceptions, by element of the SARF

\begin{tabular}{|c|c|c|c|c|}
\hline \multirow[t]{3}{*}{ Category } & \multicolumn{4}{|l|}{ SARF element } \\
\hline & Information sources and channels & Social stations & Individual stations & $\begin{array}{l}\text { Institutional and } \\
\text { social behaviour }\end{array}$ \\
\hline & $n=4$ & $n=0$ & $n=14$ & $n=0$ \\
\hline \multicolumn{5}{|l|}{ General population } \\
\hline $\begin{array}{l}\text { Factors reported to have an influ- } \\
\text { ence on risk perception }\end{array}$ & $\begin{array}{l}\text { Access to three or more information } \\
\text { sources } \\
\text { Access to community information } \\
\text { sources (e.g. community leaders, } \\
\text { friends and relatives) } \\
\text { Access to new media (e.g. internet, } \\
\text { text messages) }\end{array}$ & - & $\begin{array}{l}\text { Family size } \\
\text { Occupation } \\
\text { Belief in divine or spiritual protec- } \\
\text { tion against harm } \\
\text { Disease case fatality ratios and infec- } \\
\text { tion risks } \\
\text { Phase of an outbreak } \\
\text { Disease's responsiveness to commu- } \\
\text { nity infection control measures } \\
\text { Familiarity/novelty of disease } \\
\text { Disease severity } \\
\text { Personal self-efficacy } \\
\text { Vaccination } \\
\text { Among some high-risk occupa- } \\
\text { tional groups: knowledge of and } \\
\text { preference of a person's services/ } \\
\text { products } \\
\text { Cultural sensitivities or tendencies }\end{array}$ & 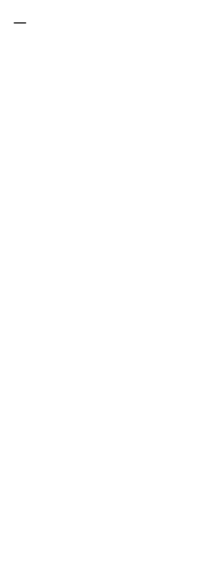 \\
\hline $\begin{array}{l}\text { Factors reported to not have an } \\
\text { influence on risk perception }\end{array}$ & - & - & $\begin{array}{l}\text { Employment status } \\
\text { Religion }\end{array}$ & - \\
\hline \multirow[t]{2}{*}{$\begin{array}{l}\text { Factors inconsistently influencing } \\
\text { risk perceptions }\end{array}$} & $\begin{array}{l}\text { Previous community experience of } \\
\text { disease } \\
\text { Newspapers, brochures and } \\
\text { billboards as epidemic information } \\
\text { sources }\end{array}$ & - & $\begin{array}{l}\text { Education level } \\
\text { Disease-specific knowledge } \\
\text { Rural or urban residence } \\
\text { Marital status } \\
\text { Income level } \\
\text { Gender } \\
\text { Age } \\
\text { Compliance with protective } \\
\text { behaviours }\end{array}$ & - \\
\hline & $n=2$ & $n=0$ & $n=2$ & $n=3$ \\
\hline \multicolumn{5}{|l|}{ Health professionals } \\
\hline $\begin{array}{l}\text { Factors reported to have an influ- } \\
\text { ence on risk perception }\end{array}$ & $\begin{array}{l}\text { Disease-specific knowledge e.g. } \\
\text { through training }\end{array}$ & - & $\begin{array}{l}\text { Familiarity with clinical presentation } \\
\text { Speed of disease spread } \\
\text { Predictability of outbreak } \\
\text { Availability of a pharmacological } \\
\text { cure } \\
\text { Possibility of encounters with } \\
\text { infected patients } \\
\text { Witnessing deaths among col- } \\
\text { leagues } \\
\text { Potential to spread infection to oth- } \\
\text { ers in the community }\end{array}$ & $\begin{array}{l}\text { Efficacy of health } \\
\text { system response } \\
\text { Access to vaccina- } \\
\text { tion } \\
\text { Existence of vac- } \\
\text { cine research }\end{array}$ \\
\hline $\begin{array}{l}\text { Factors reported to not have an } \\
\text { influence on risk perception }\end{array}$ & - & - & - & - \\
\hline $\begin{array}{l}\text { Factors inconsistently influencing } \\
\text { risk perceptions }\end{array}$ & - & - & - & - \\
\hline
\end{tabular}

-: blank; SARF: social amplification of risk framework

presentations [76], the rapid spread and unpredictable nature of an outbreak, and diseases without a pharmacological cure, such as EVD [72].

Within the clinical environment, health professionals reported that encounters with infected patients [76], witnessing colleagues die [76], and the potential to spread infection to others in the community [72] all increased their fear. 


\section{Institutional response}

Health professionals reported a number of factors associated with the health system response that influenced perceived risk. These included indicators of institutional efficacy that alleviate fear, such as clear protocols and operating procedures for patient triage and isolation, the presence of experts and role models early on in the response, availability of personal protective equipment (PPE), rapid and early diagnostic tools, non-contact thermometers and sufficient handwashing and disinfection supplies and facilities $[72,76]$. The studies also reported that access to vaccination [70], and vaccine research and development for diseases such as EVD [76] reduce perceived susceptibility among health workers.

Table 5 summarizes the factors reported by eligible studies and their influence of epidemic risk perceptions among health professionals, by element of the SARF.

\section{Conceptualisation and measurement of epidemic risk perceptions $(n=56)$}

Studies applied variable conceptualisations of risk perception, as reflected in data collection instruments and wording of questions. For perceived likelihood, thirtyfour studies conceived of this as research participants themselves contracting infection, while other studies asked participants about the likelihood of others getting infected. Twenty-seven studies used the term "risk" while other studies asked respondents about "possibility", "probability", or "chance". Only three studies provided time windows in their questions, for example, risk over the next 6 months. Perceived susceptibility was conceptualised by two studies as the likelihood of contracting infections in the absence of preventive measures, and by another two studies as the comparative susceptibility among groups. For perceived severity, nineteen studies operationalised this as 'seriousness' or 'dangerousness' of the disease. Other studies asked participants about the likelihood of certain outcomes (recovery, survival, severe illness, death) should they be infected. Finally, for affective perception, thirteen studies measured 'fear' or 'worry'. Two studies asked the research participant about emotions (e.g. fear or worry) towards their family members, and one study asked participants about the threat to their community, district and country.

Likert-type or Likert scales, ranging from 3- to 10-point scales, were by far the most commonly-used tool for risk perceptions across all conceptualisations. However, the use of neutral or 'don't know' categories was inconsistent. Furthermore, some scales measured degrees or levels of "risk" while others measured respondents' levels of agreement with statements. This heterogeneity in measurement modalities, measured aspects and wording limited comparability between studies. Furthermore, for several papers we could not ascertain the measurement method used.

Details of the conceptual frameworks, definitions and measurement of risk perception used by eligible studies are provided in Table 6.

\section{Quality of evidence}

Of the fifty-six eligible studies, we graded forty as good, twelve as acceptable and four as poor quality. The results of quality appraisal of eligible papers are presented in Additional file 2.

Among cross-sectional studies $(n=45)$, the most common weakness was not categorising, addressing or describing non-responders, or commenting on potential non-response bias. Similarly, among five qualitative studies and two mixed methods studies, none reported on the numbers or reasons of those who chose not to participate.

Among qualitative studies $(n=5)$, there was generally a lack of information on the studies' ethical procedures, such as for informed consent or safeguarding confidentiality and anonymity. Among mixed methods studies $(n=6)$, none adequately addressed divergences and inconsistencies between qualitative and quantitative data.

\section{Discussion}

To the best of our knowledge, this is currently the only systematic review to examine the evidence of epidemic risk perceptions in populations that are highly vulnerable to epidemics. The review highlights that, despite a moderate body of evidence, major gaps remain. Studies from only eighteen of the 62 eligible countries were identified. Diseases that cause frequent epidemics in these settings [30], such as measles or cholera, received little or no attention. This finding is similar to previous research suggesting that epidemics of common diseases are less likely to be responded to in a timely manner [84], or to be evaluated [30].

This review set out to identify how a context of frequent and often concurrent epidemics influences epidemic risk perceptions. Research on non-communicable and heritable diseases suggests that perceived risk of a disease influences the perceived risk of other diseases, and that the perceived risk does not necessarily correspond to the actual risk posed by a disease [85-87]. However, only three studies in our review compared the perception of two or more epidemic-prone diseases in the same population, and two studies explored the influence of familiarity and novelty of a disease on risk perception. Furthermore, none specifically explored the influence of the high-vulnerability context on epidemic risk perceptions. Our review highlights the need for research that explores epidemic risk perception construction in the 


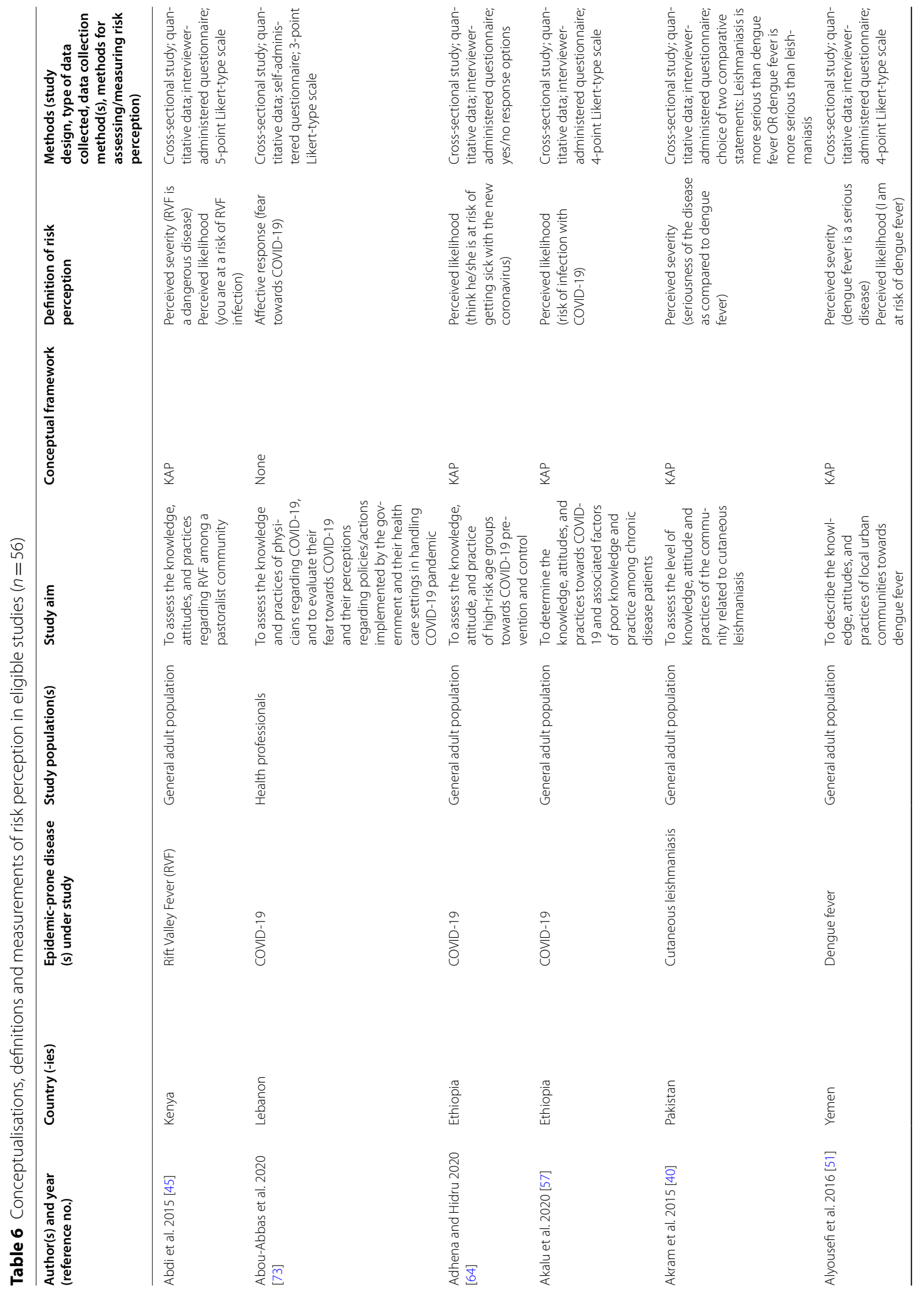




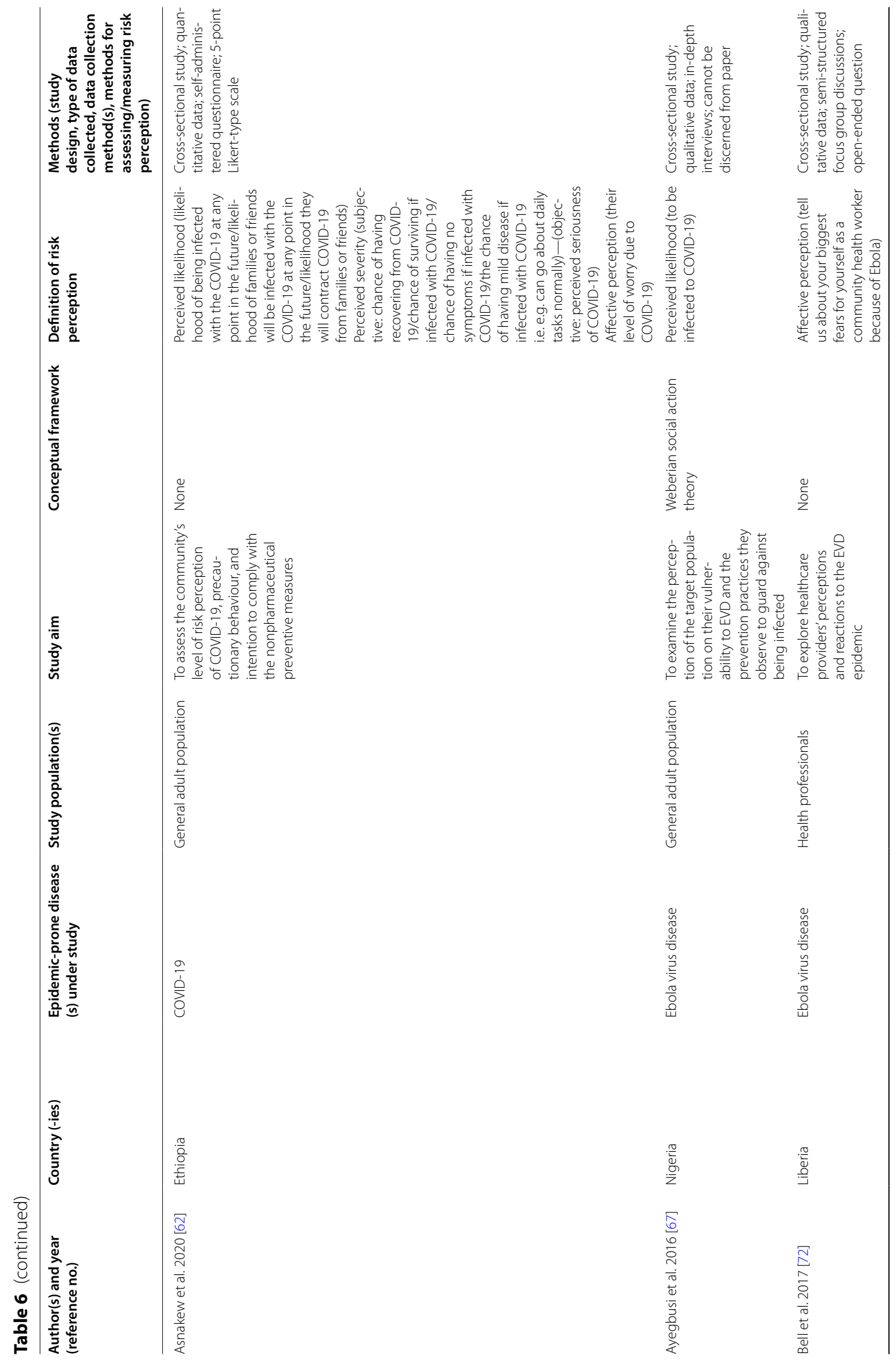




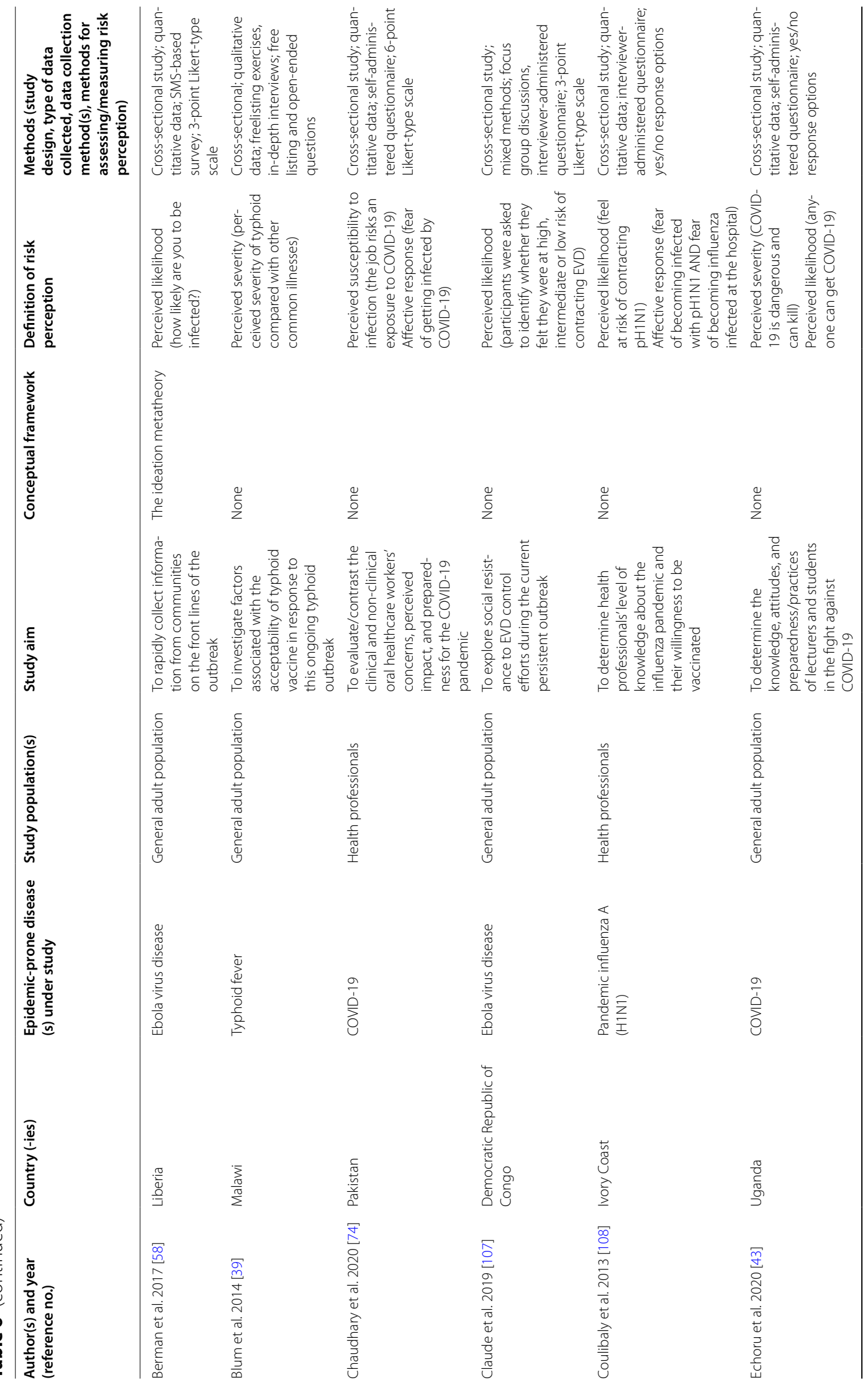




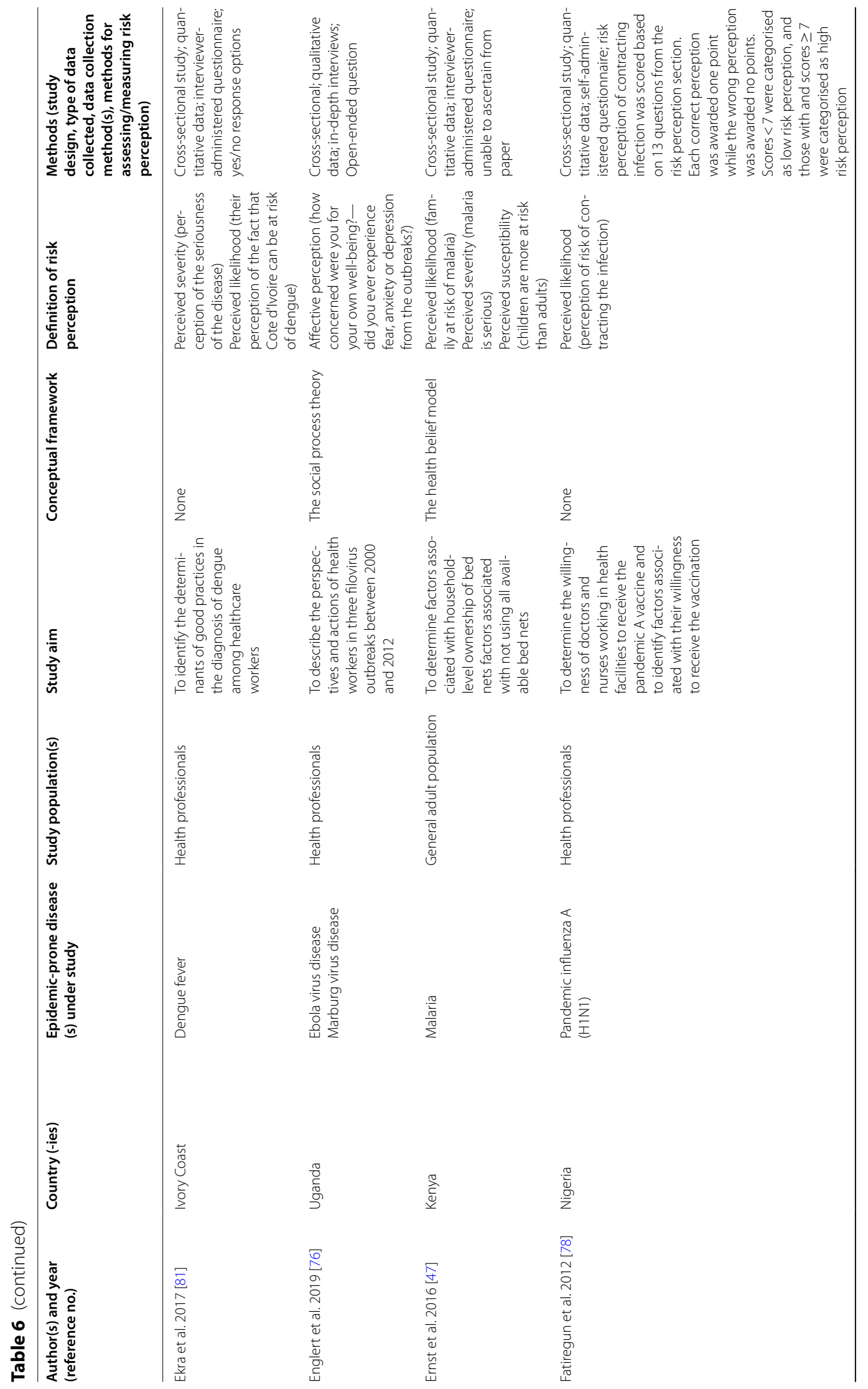




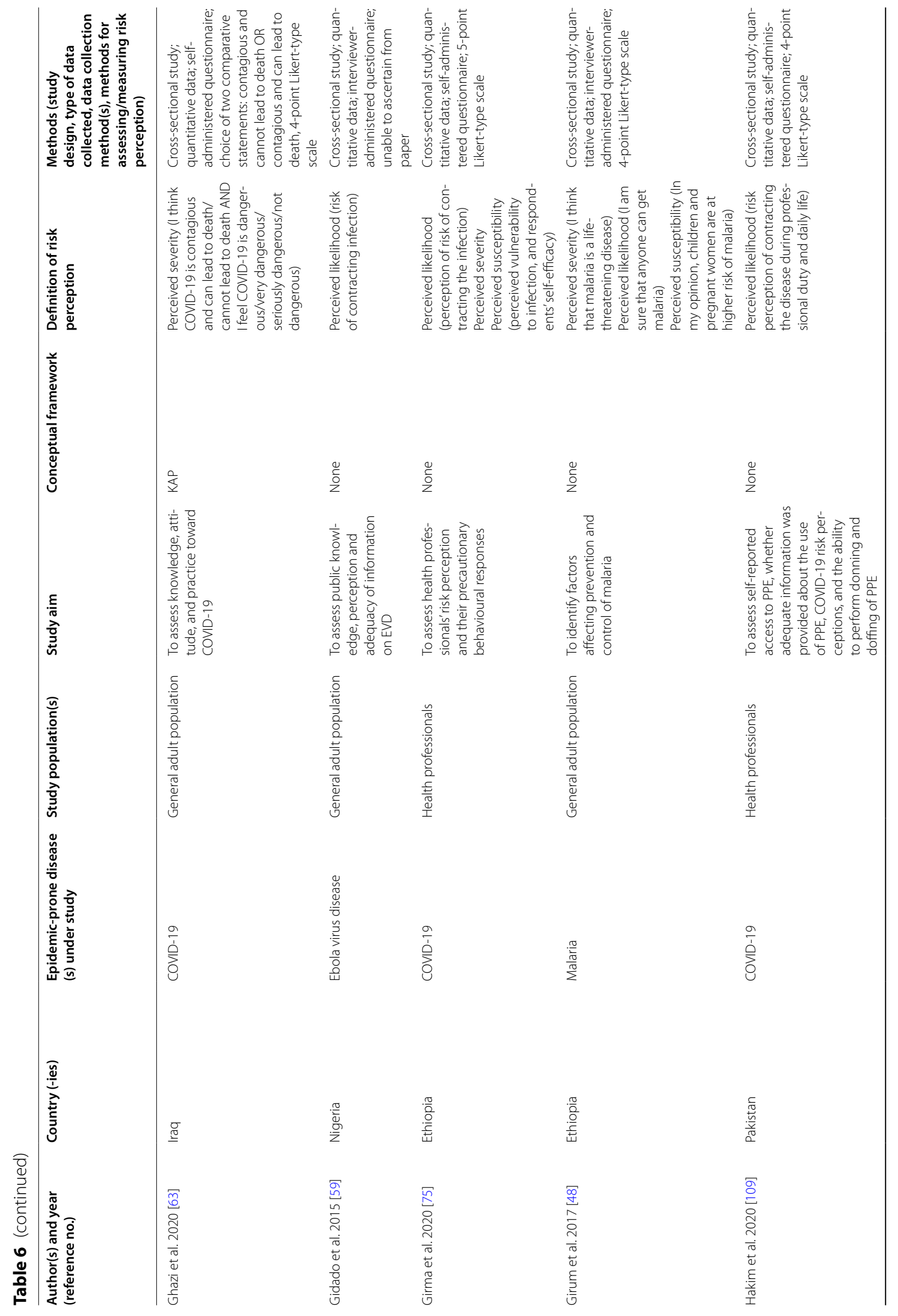




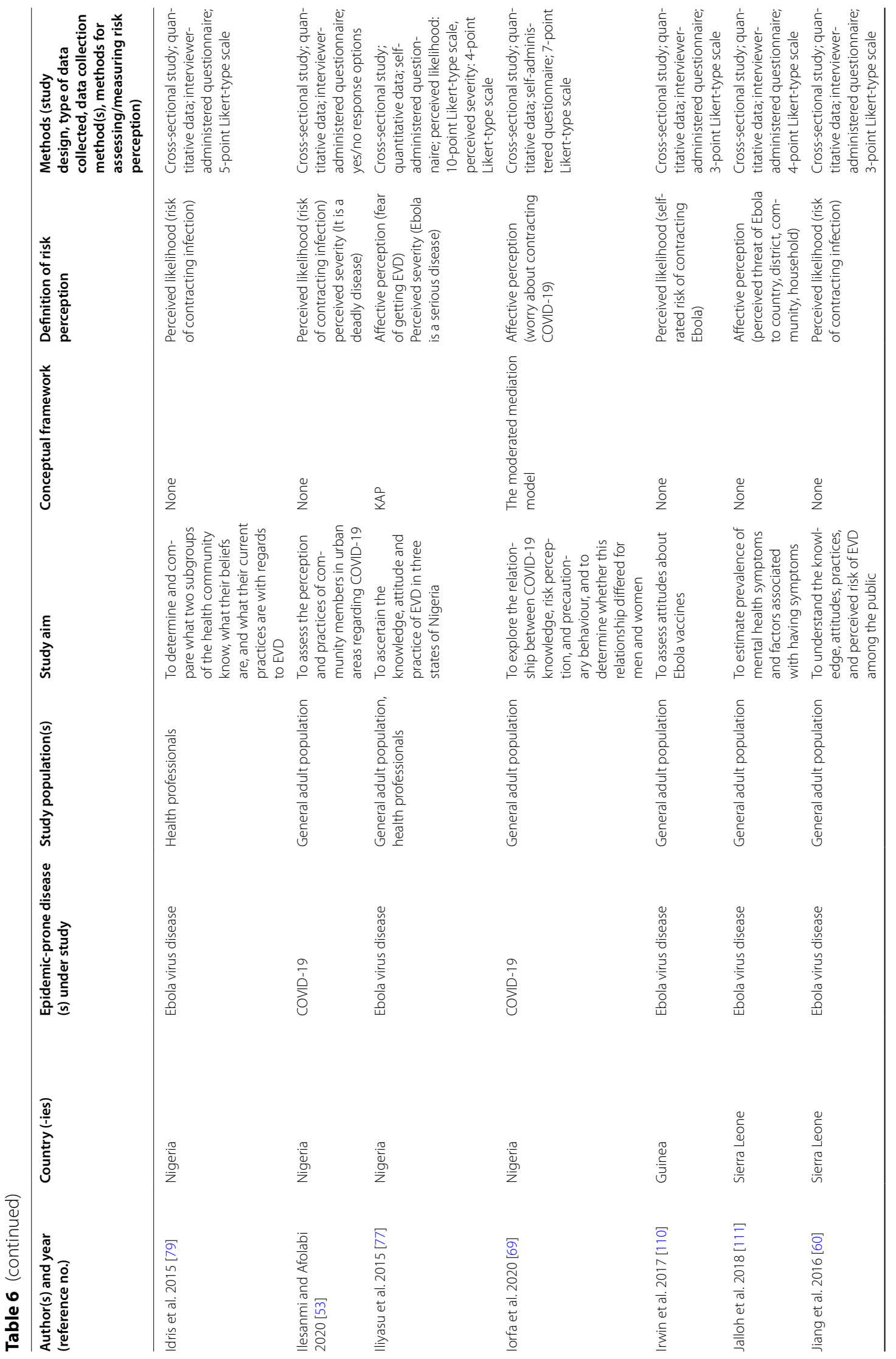




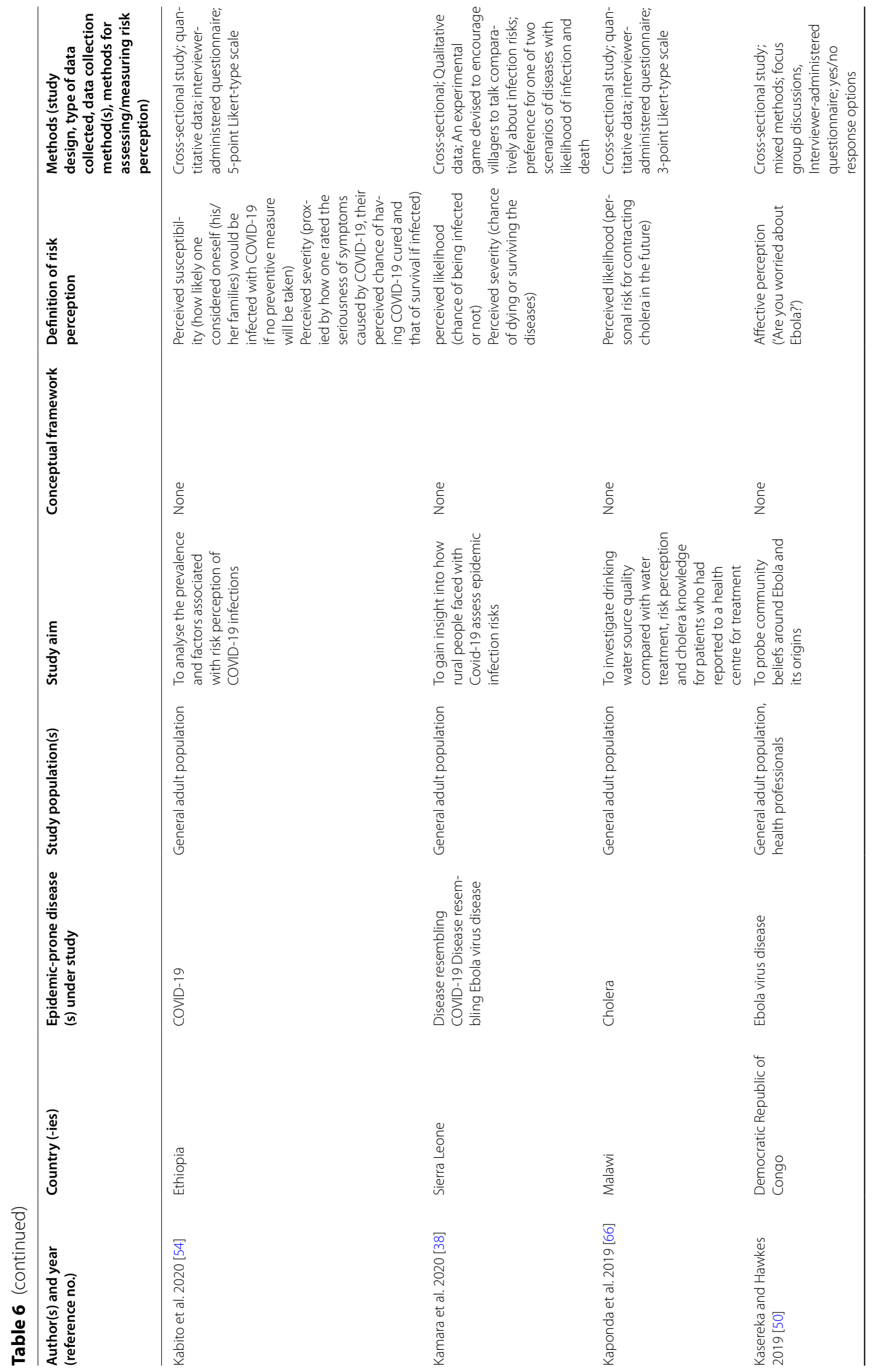




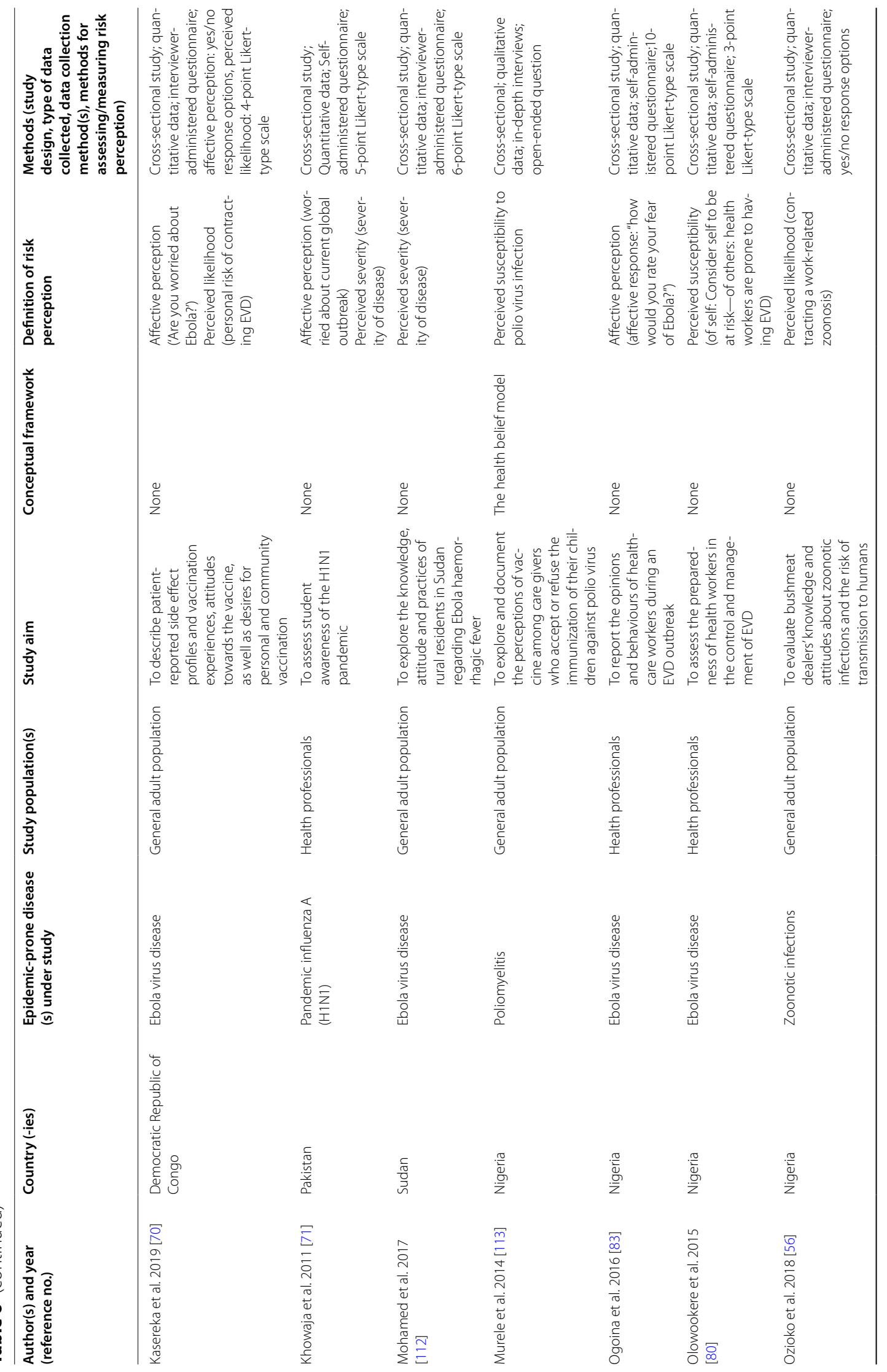




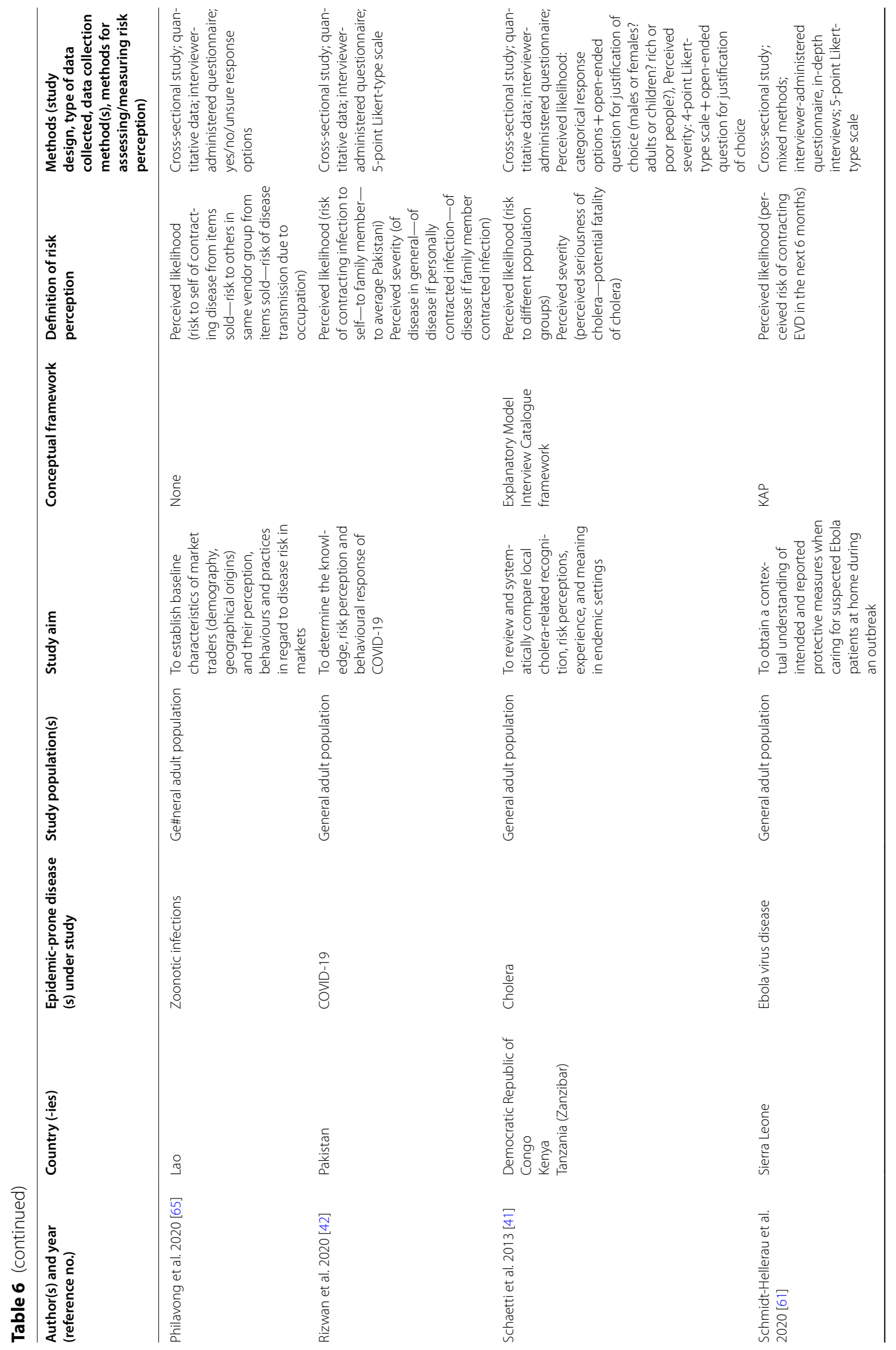




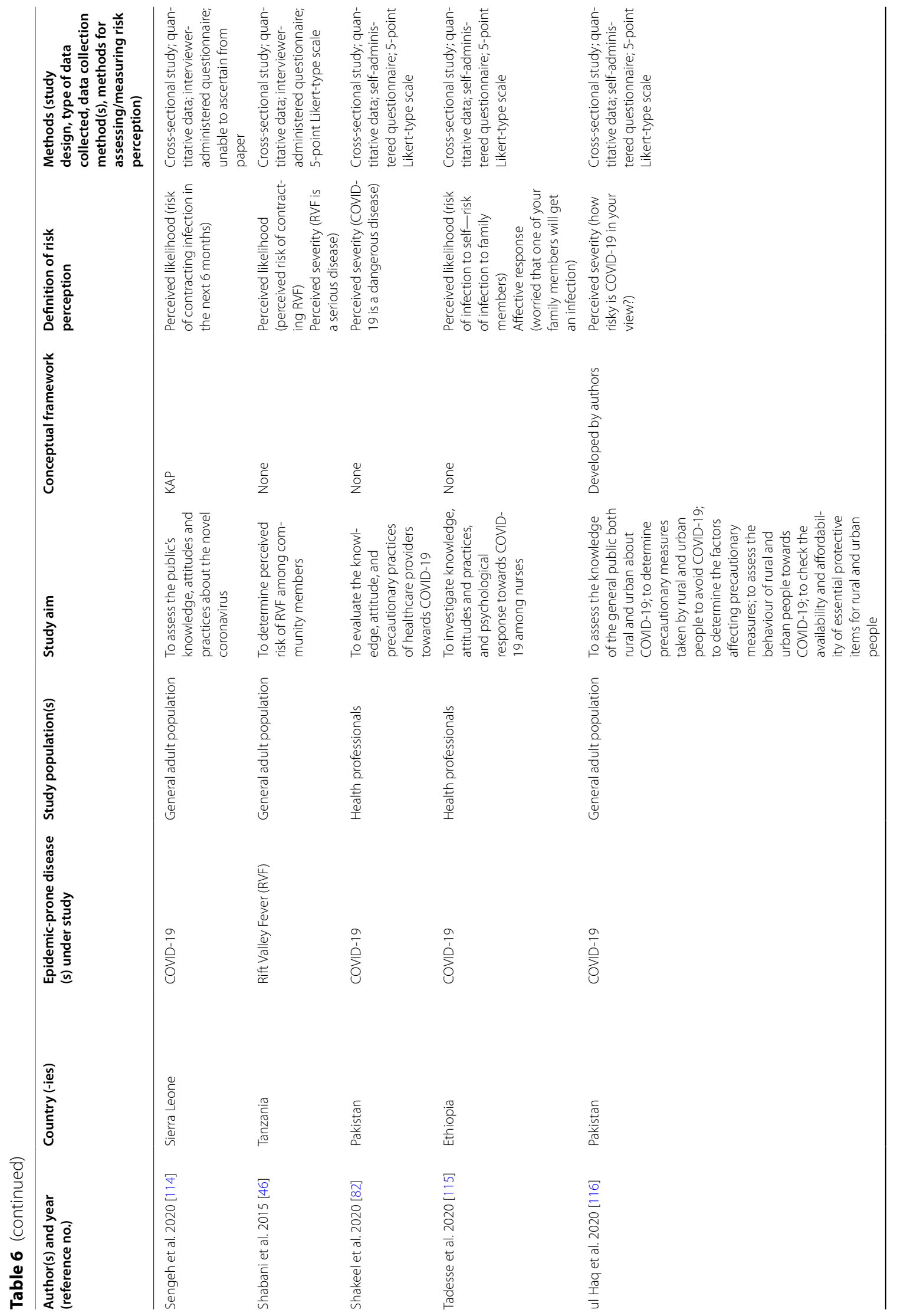




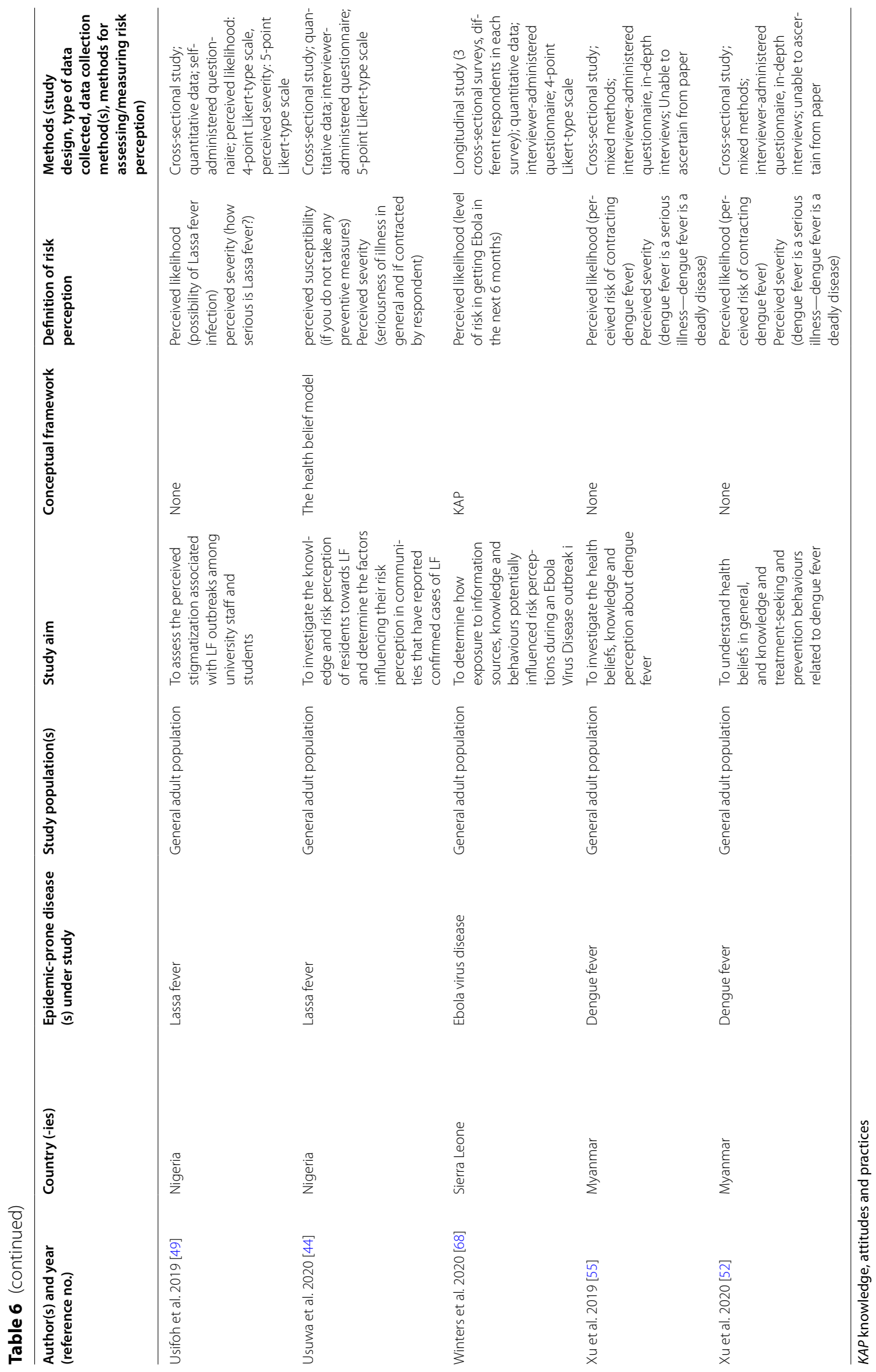


broader context of living in a setting with frequent and multiple epidemics.

\section{Factors influencing epidemic risk perceptions}

The review findings suggest that the general population consistently perceived their likelihood of acquiring infections as lower than they rated the severity of diseases, and they were more likely to perceive the risk of infection to others as higher than to themselves. Occupational groups with high exposure to specific diseases, such as bushmeat handlers, reported even lower perceived likelihood than the general population, and similarly perceived the risk of infection to other members of their trade as higher than to themselves. This phenomenon of lower perceived likelihood, termed 'unrealistic optimism' [88] and described as a cognitive bias, is often observed in the general population across cultures [89]. Optimistic bias has been found to particularly occur in a comparative assessment with risk to others [90], and during active outbreaks [91]. Our findings suggest that unrealistic optimism among some high-risk occupational groups may be explained by the long-term and well-established uses of their products and services. Epidemic responders should consider how unrealistic optimism could hinder risk communication, particularly when designing communication strategies that incorporate social comparisons of risk.

By contrast, perceived likelihood of infection was generally high amongst health professionals, though findings were inconclusive when comparing perceived risk to self with risk to colleagues. This group mainly cited concerns about their employing institutions' ability to create a safe and effective work environment, and the effectiveness of the broader health system response, described by the SARF as the influence of the organisational response or behaviour on risk perception modification. The influence of perceived health system disaster response capacity on risk perception has been reported among health professionals in better-resourced settings, such as Singapore, Saudi Arabia and Canada [92-94]. However, factors other than organisational effectiveness remain insufficiently explored. These include the socio-cultural context and different information sources and channels, particularly in conditions of scientific uncertainty about the disease in question. Risk communication interventions to modify health professionals' epidemic risk perceptions should therefore be accompanied with measures to enhance safety in the workplace.

Our findings suggest risk perception is influenced by disease characteristics, especially disease severity, familiarity, controllability and phase of an outbreak. Analogous associations feature at the core of Slovic's psychometric paradigm [95] and Covello's four theoretical risk communications models [96], to describe the psychological processes of risk perception formation. However, the SARF extends this further to explain how individuals or groups select specific characteristics of the risk, interpret them and communicate them to others, and how this selection varies across different settings and risks. Our review suggests that some information sources may be more influential than others, and that this variation may be due to different sources highlighting different disease attributes in their messages. Further research is needed into why certain disease characteristics become salient in settings with frequent epidemics, and how communication channels and content may mediate the relationship between disease characteristics and risk perception formation.

Review findings suggest that evidence on the influence of demographic factors on risk perception is inconclusive. This may indicate the diversity in conceptualisation and methods of measuring risk perception used by the studies in our review. Previous research suggests that age differences in risk may vary across the domain of risk under investigation-for example, different age groups may interpret disease 'severity' in terms of its health, social or economic consequences and therefore give different responses [97]. Similarly, gender differences in risk perception are reported to be sensitive to methodological approaches-for example, while women consistently demonstrate higher risk perceptions for all risks, gender differences are not observed when respondents are asked to rank hazards in order of severity or seriousness [98]. The findings suggest that risk communication interventions targeting a specific demographic should account for heterogeneous risk perceptions within that group.

The review suggests that there is insufficient evidence on how epidemic risk perceptions are formed or modified in these populations. Only a third of eligible studies in our review reported on factors influencing risk perceptions. In general, there was lack of depth to the inquiry in the studies. This may be due to most studies being crosssectional and quantitative, precluding exploration of why people perceived what they did, and how and why risk perceptions varied between diseases, populations and over time. Studies among the public primarily focused on individual constructions of risk, such as the influence of disease attributes and socio-demographic variables, but few studies explored the role of information sources and channels, cultural factors, and none studied the influence of perceptions of the epidemic response. In contrast, studies among health professionals primarily investigated the influence of institutional efficacy on risk perception. Furthermore, the studies in our reported on the independent influence of selected factors on risk perception, but none explored the interaction between these factors to shed light on the complex process of risk perception 
formation or adaptation. Further research is needed to explore the differences in epidemic risk perceptions between population groups, particularly the social and cultural processes that intensify or attenuate perceptions of the disease risk and its manageability.

\section{Conceptualisation and measurement of epidemic risk perceptions}

Our review finds that, while epidemic risk perceptions are measured in a moderate number of studies across disciplines, there is wide variation in the conceptualisation of risk perception by researchers. Overall, the review revealed limited engagement with the concept of risk perception and only a third used conceptual frameworks or models to situate their hypotheses and findings. The authors' conceptualisations of risk perception were mostly deduced from the study variables, instruments or results. None of the studies acknowledged the effect of question wording on how respondents may rate or describe their perceived risk [99]. This is particularly relevant in settings where studies were not conducted in the English language, since the conceptualisation of risk varies widely across cultures and languages [100].

The operational definition of epidemic risk perception varied widely across studies, ranging from unidimensional or single item measures to multidimensional composite risk perception scores. Our findings indicate that most researchers measure one dimension of risk perception, usually likelihood, whereas only a minority measure a combination of dimensions, such as likelihood, severity and vulnerability. Few researchers combined measurements of probability judgements, such as likelihood and vulnerability, with consequential judgements, such as affect/feelings or severity. In their review of hazard risk perception measurement methods, Wilson et al. reported that almost half of studies measured only one dimension of risk perception, often perceived likelihood, and argued that this unidimensional approach is not particularly valid or reliable for understanding individual risk perception formation [101].

Even where different studies used the same conceptual frameworks or risk perceptions definitions, diverse measurement methods limited comparisons. It was difficult to interpret whether there were actual differences in risk perception between diseases, countries or populations, or whether observed inconsistencies were due to methodological design. For example, many eligible studies used Likert-type scales to capture risk perception responses, but the inconsistent use of 'don't know' response categories by researchers complicated the interpretation of findings. Previous research indicates that a nonnegligible proportion of study respondents report not knowing their risk of diseases in studies, particularly in populations that are socio-economically disadvantaged or with health disparities [102].

While the vast majority of studies in our review were deemed of good or acceptable quality by standardised quality appraisal tools, in general, there was lack of depth to the inquiry. This may be due to the fact that the majority of studies evaluated in this review used a cross-sectional design, with most being quantitative studies, and therefore lacking in-depth and longitudinal exploration of why people perceived what they did, and if, how and why risk perceptions varied between diseases, populations and over time. Furthermore, the high level of heterogeneity in methods, tools and measurement scales in eligible studies prevented a definitive identification of factors associated with epidemic risk perceptions. Varying conceptualisations, definitions and measurements of health risk perceptions and behaviours have previously been shown to hamper cross-study comparisons $[13,20$, 103].

\section{Review limitations}

Screening and selection were conducted by a single reviewer, and may have resulted in some eligible studies being missed. To mitigate this risk, the reviewer erred on the side of caution and included items with unclear eligibility in the second stage of screening. We did not include grey literature which may have provided additional and valuable insights, particularly publications by humanitarian responders serving populations in eligible countries. Due to the heterogeneity in outcomes and study methods, only a narrative analysis and synthesis was feasible. Furthermore, it was not feasible to contextualise all of the findings from the diverse set of epidemic-prone diseases, countries and population groups included in this review; instead, we attempted to identify and describe key themes that could be useful to researchers and epidemic responders. Finally, there were limitations posed by methodological weaknesses in a minority of included studies, mainly related to non-response, ethical considerations and a lack of information on inconsistencies between qualitative and quantitative epidemic risk perception data.

\section{Conclusions}

This review suggests that evidence on epidemic risk perception in countries at the highest risk of these public health emergencies is limited. Available studies afford some insight into patterns of epidemic risk perception and factors influencing its formation, but the quality and validity of these findings are affected by a lack of in-depth inquiry and exploration. There are several areas in particular that require more attention from researchers. First, risk perceptions of diseases 
that cause frequent epidemics in these settings, such as measles and cholera, should be given more attention and explored in-depth to better inform responses. Second, studies comparing perceptions of different epidemic-prone diseases in the same population, or comparing perceptions across different populations or settings are essential for better contextualisation of risk perception understanding. Third, research that adopts a comprehensive, theory-driven, and preferably longitudinal, exploration of epidemic risk perception construction is needed, particularly to situate risk perceptions in the broader context of living in a setting with frequent and multiple epidemics.

The review also suggests that the science of defining and measuring epidemic risk perception is still relatively underdeveloped. First, there is a need for promotion of best practices in measuring risk perceptions, such as the systematic inclusion of 'don't know' categories in risk perception measurement scales. Such standardisation will facilitate comparisons among studies and allow for systematic accumulation of evidence. Second, more research that explores or measures multiple dimensions of epidemic risk perceptions is needed, such as studies that simultaneously explore perceived probability, vulnerability and severity.

\section{Abbreviations \\ AXIS: Appraisal tool for cross-sectional studies; COVID-19: Coronavirus disease; EVD: Ebola virus disease; H1N1: Pandemic influenza A; IDP: Internally-displaced person; KAP: Knowledge, attitudes and practices; MMAT: Mixed methods appraisal tool; PPE: Personal protective equipment; SARF: Social amplification of risk framework.}

\section{Supplementary Information}

The online version contains supplementary material available at https://doi. org/10.1186/s40249-021-00927-z.

Additional file 1. Search terms, and search strategy and results by database.

Additional file 2. Quality appraisal of eligible studies $(n=56)$.

\section{Acknowledgements}

We thank Dr. Jennifer Palmer and Ms. Sian White for their suggestions on the framing and presentation of the review's findings.

\section{Authors' contributions}

This study was conceptualised and designed by NA and BR. The data collection, cleaning and analysis was undertaken by NA. All authors contributed to the writing of the first draft. All authors read and approved the final manuscript.

\section{Funding}

This work was supported by UK Research and Innovation as part of the Global Challenges Research Fund, Grant Number ES/P010873/. The funder did not have any role in the design of the study and collection, analysis, and interpretation of data and in writing the manuscript.
Availability of data and materials

All data generated or analysed during this study are included in this published article and its additional information files.

\section{Declarations}

Ethics approval and consent to participate

Not applicable.

\section{Consent for publication}

Not applicable.

\section{Competing interests}

The authors declare that they have no competing interests.

\section{Author details}

${ }^{1}$ Faculty of Public Health \& Policy, London School of Hygiene \& Tropical Medicine, 15-17 Tavistock Place, London WC1H 9SH, UK. ${ }^{2}$ Faculty of Epidemiology and Population Health, London School of Hygiene \& Tropical Medicine, Keppel Street, London WC1E 7HT, UK.

Received: 9 August 2021 Accepted: 16 December 2021

Published online: 06 January 2022

\section{References}

1. Norheim OF, Jha P, Admasu K, Godal T, Hum RJ, Kruk ME, et al. Avoiding $40 \%$ of the premature deaths in each country, 2010-30: review of national mortality trends to help quantify the UN sustainable development goal for health. Lancet. 2015;385(9964):239-52. https://doi.org/ 10.1016/50140-6736(14)61591-9.

2. World Health Organization. Managing epidemics: key facts about major deadly diseases. Geneva: World Health Organization; 2018.

3. World Health Organization. International health regulations (2005). 3rd ed. Geneva: World Health Organization; 2005.

4. Cameron EE, Nuzzo JB, Bell JA, Nalabandian M, O'Brien J, League A, et al. Global health security index: building collective action and accountability. Nuclear threat initiative 2019. https://www.ghsindex.org/reportmodel/. Accessed 15 Dec 2020.

5. Moore M, Gelfeld B, Okunogbe AT, Paul C. Identifying future disease hot spots: infectious disease vulnerability index. Santa Monica: RAND Corporation; 2016.

6. Gupta V, Kraemer JD, Katz R, Jha AK, Kerry VB, Sane J, et al. Analysis of results from the joint external evaluation: examining its strength and assessing for trends among participating countries. J Glob Health. 2018;8(2): 020416. https://doi.org/10.7189/jogh.08.020416.

7. Oppenheim B, Gallivan M, Madhav NK, Brown N, Serhiyenko V, Wolfe $\mathrm{ND}$, et al. Assessing global preparedness for the next pandemic: development and application of an epidemic preparedness index. BMJ Glob Health. 2019;4(1): e001157. https://doi.org/10.1136/ bmjgh-2018-001157.

8. Becker MH. The health belief model and sick role behavior. Health Educ Monogr. 1974;2(4):409-19. https://doi.org/10.1177/109019817400200 407.

9. Rogers RW. A protection motivation theory of fear appeals and attitude change1. J Psychol. 1975;91(1):93-114. https://doi.org/10.1080/00223 980.1975.9915803.

10. Witte K. Putting the fear back into fear appeals: the extended parallel process model. Commun Monogr. 1992;59(4):329-49. https://doi.org/ 10.1080/03637759209376276.

11. Rimal R. Perceived risk and efficacy beliefs as motivators of change: use of the risk perception attitude (RPA) framework to understand health behaviors. Hum Commun Res. 2003;29:370-99. https://doi.org/10.1093/ hcr/29.3.370.

12. Brewer NT, Chapman GB, Gibbons FX, Gerrard M, McCaul KD, Weinstein ND. Meta-analysis of the relationship between risk perception and health behavior: the example of vaccination. Health Psychol. 2007;26(2):136-45. https://doi.org/10.1037/0278-6133.26.2.136. 
13. Gaube S, Lermer E, Fischer P. The concept of risk perception in healthrelated behavior theory and behavior change. In: Raue M, Streicher B, Lermer E, editors. Perceived safety: a multidisciplinary perspective. Cham: Springer International Publishing; 2019. p. 101-18.

14. Sheeran P, Harris PR, Epton T. Does heightening risk appraisals change people's intentions and behavior? A meta-analysis of experimental studies. Psychol Bull. 2014;140(2):511-43. https://doi.org/10.1037/a0033 065.

15. Atkinson TM, Salz T, Touza KK, Li Y, Hay JL. Does colorectal cancer risk perception predict screening behavior? A systematic review and meta-analysis. J Behav Med. 2015;38(6):837-50. https://doi.org/10.1007/ s10865-015-9668-8.

16. Slovic P. Perception of risk. Science. 1987;236(4799):280. https://doi.org/ 10.1126/science.3563507.

17. Douglas M, Wildavsky A. Risk and culture an essay on the selection of technological and environmental dangers. 1st ed. Berkeley: University of California Press; 1982.

18. Kasperson R, Renn O, Slovic P, Brown HS, Emel J, Goble R, et al. The social amplification of risk: a conceptual framework. Risk Anal. 1988:8:177-87.

19. World Health Organization. Communicating risk in public health emergencies. Geneva: World Health Organization; 2018.

20. Ferrer RA, Klein WMP. Risk perceptions and health behavior. Curr Opin Psychol. 2015;5:85-9. https://doi.org/10.1016/j.copsyc.2015.03.012.

21. Reyna VF, Nelson WL, Han PK, Dieckmann NF. How numeracy influences risk comprehension and medical decision making. Psychol Bull. 2009;135(6):943-73. https://doi.org/10.1037/a0017327.

22. Lujala P, Lein H, Rød JK. Climate change, natural hazards, and risk perception: the role of proximity and personal experience. Local Environ. 2015;20(4):489-509. https://doi.org/10.1080/13549839.2014.887666.

23. World Health Organization. World health report: reducing risks, increasing healthy lives. Geneva: World Health Organization; 2002.

24. Sullivan-Wiley KA, Short Gianotti AG. Risk perception in a multi-hazard environment. World Dev. 2017;97:138-52. https://doi.org/10.1016/j. worlddev.2017.04.002.

25. Doss C, McPeak J, Barrett CB. Interpersonal, intertemporal and spatial variation in risk perceptions: evidence from East Africa. World Dev. 2008;36(8):1453-68. https://doi.org/10.1016/j.worlddev.2007.06.023.

26. Smith K, Barrett CB, Box PW. Not necessarily in the same boat: heterogeneous risk assessment among east African pastoralists. J Dev Stud. 2001;37(5):1-30. https://doi.org/10.1080/00220380412331322101.

27. Schiavo R, May Leung M, Brown M. Communicating risk and promoting disease mitigation measures in epidemics and emerging disease settings. Pathog Glob Health. 2014;108(2):76-94. https://doi.org/10.1179/ 2047773214Y.0000000127.

28. Moher D, Liberati A, Tetzlaff J, Altman DG. Preferred reporting items for systematic reviews and meta-analyses: the PRISMA statement. Ann Intern Med. 2009;151(4):264-9. https://doi.org/10.7326/0003-4819-1514-200908180-00135.

29. Bruckner C, Checchi F. Detection of infectious disease outbreaks in twenty-two fragile states, 2000-2010: a systematic review. Confl Health. 2011;5(1):13. https://doi.org/10.1186/1752-1505-5-13.

30. Warsame A, Murray J, Gimma A, Checchi F. The practice of evaluating epidemic response in humanitarian and low-income settings: a systematic review. BMC Med. 2020;18(1):315. https://doi.org/10.1186/ s12916-020-01767-8.

31. Warren EA, Paterson P, Schulz WS, Lees S, Eakle R, Stadler J, et al. Risk perception and the influence on uptake and use of biomedical prevention interventions for HIV in sub-Saharan Africa: a systematic literature review. PLoS ONE. 2018;13(6): e0198680. https://doi.org/10.1371/journ al.pone.0198680.

32. Downes MJ, Brennan ML, Williams HC, Dean RS. Development of a critical appraisal tool to assess the quality of cross-sectional studies (AXIS). BMJ Open. 2016;6(12): e011458. https://doi.org/10.1136/bmjop en-2016-011458.

33. Clark JP. How to peer review a qualitative manuscript. In: Godlee F, Jefferson T, editors. Peer review in health sciences. 2nd ed. London: BMJ Books; 2003. p. 219-35.

34. Pluye P, Hong QN. Combining the power of stories and the power of numbers: mixed methods research and mixed studies reviews. Annu
Rev Public Health. 2014;35(1):29-45. https://doi.org/10.1146/annurevpublhealth-032013-182440.

35. Renn O. Risk communication and the social amplification of risk. In: Kasperson RE, Stallen P, editors. Communicating risks to the public: technology, risk, and society. An International Series in Risk Analysis. Dordrecht: Springer; 1991.

36. Pidgeon N, Kasperson RE, Slovic P. The social amplification of risk. Cambridge: Cambridge University Press; 2003.

37. Renn O, Burns WJ, Kasperson JX, Kasperson RE, Slovic P. The social amplification of risk: theoretical foundations and empirical applications. J Soc Issues. 1992;48(4):137-60. https://doi.org/10.1111/j.1540-4560. 1992.tb01949.x.

38. Kamara FM, Mokuwa EY, Richards P. How villagers in central Sierra Leone understand infection risks under threat of COVID-19. PLoS ONE. 2020;15(6): e0235108. https://doi.org/10.1371/journal.pone.0235108.

39. Blum LS, Dentz H, Chingoli F, Chilima B, Warne T, Lee C, et al. Formative investigation of acceptability of typhoid vaccine during a typhoid fever outbreak in Neno District, Malawi. Am J Trop Med Hyg. 2014;91(4):729_ 37. https://doi.org/10.4269/ajtmh.14-0067.

40. Akram A, Khan HAA, Qadir A, Sabir AM. A cross-sectional survey of knowledge, attitude and practices related to cutaneous leishmaniasis and sand flies in Punjab, Pakistan. PLoS ONE. 2015;10(6): e0130929. https://doi.org/10.1371/journal.pone.0130929.

41. Schaetti C, Sundaram N, Merten S, Ali SM, Nyambedha EO, Lapika B, et al. Comparing sociocultural features of cholera in three endemic African settings. BMC Med. 2013;11:16. https://doi.org/10.1186/ 1741-7015-11-206.

42. Rizwan W, Sadiq M, Mushtaq A, Lodhi AM, Awan ZR, Rana MN. Knowledge, risk perception and behavioral response of COVID-19 among the general population attending children's hospital, Lahore. Ann King Edward Med Univ Lahore Pak. 2020;26:276-83.

43. Echoru I, Kasozi KI, Usman IM, Mutuku IM, Ssebuufu R, Ajambo PD, et al. University lecturers and students could help in community education about SARS-CoV-2 infection in Uganda. Health Serv Insights. 2020. https://doi.org/10.1177/1178632920944167.

44. Usuwa IS, Akpa CO, Umeokonkwo CD, Umoke M, Oguanuo CS, Olorukooba AA, et al. Knowledge and risk perception towards Lassa fever infection among residents of affected communities in Ebonyi State, Nigeria: implications for risk communication. BMC Public Health. 2020;20(1):217. https://doi.org/10.1186/s12889-020-8299-3.

45. Abdi IH, Affognon HD, Wanjoya AK, Onyango-Ouma W, Sang R. Knowledge, attitudes and practices (KAP) on Rift Valley fever among pastoralist communities of ljara District, North Eastern Kenya. PLoS Negl Trop Dis. 2015;9(11): e0004239. https://doi.org/10.1371/journal.pntd. 0004239.

46. Shabani SS, Ezekiel MJ, Mohamed M, Moshiro CS. Knowledge, attitudes and practices on Rift Valley fever among agro pastoral communities in Kongwa and Kilombero districts, Tanzania. BMC Infect Dis. 2015;15(1):363. https://doi.org/10.1186/s12879-015-1099-1.

47. Ernst KC, Hayden MH, Olsen H, Cavanaugh JL, Ruberto I, Agawo M, et al. Comparing ownership and use of bed nets at two sites with differential malaria transmission in western Kenya. Malar J. 2016;15:217. https://doi. org/10.1186/s12936-016-1262-1.

48. Girum T, Hailemikael G, Wondimu A. Factors affecting prevention and control of malaria among endemic areas of Gurage zone: an implication for malaria elimination in South Ethiopia, 2017. Trop Dis Travel Med Vaccines. 2017;3(1):17. https://doi.org/10.1186/s40794-017-0060-2.

49. Usifoh SF, Odigie AE, Ighedosa SU, Uwagie-Ero EA, Aighewi IT. Lassa fever-associated stigmatization among staff and students of the university of Benin, Nigeria. J Epidemiol Glob Health. 2019;9(2):107-15. https://doi.org/10.2991/jegh.k.190514.001.

50. Kasereka MC, Hawkes MT. 'The cat that kills people:' community beliefs about Ebola origins and implications for disease control in Eastern Democratic Republic of the Congo. Pathog Glob Health. 2019;113(4):149-57. https://doi.org/10.1080/20477724.2019.1650227.

51. Alyousefi TAA, Abdul-Ghani R, Mahdy MAK, Al-Eryani SMA, Al-Mekhlafi AM, Raja YA, et al. A household-based survey of knowledge, attitudes and practices towards dengue fever among local urban communities in Taiz Governorate, Yemen. BMC Infect Dis. 2016;16(1):543.

52. Xu JW, Liu H, Yaw B, Nbwi HS. The health beliefs, dengue knowledge and control behaviors among internally displaced persons versus local 
residents in kachin special region II, Myanmar. PLoS Negl Trop Dis. 2020;14(6):1-14. https://doi.org/10.1371/journal.pntd.0008321.

53. Ilesanmi O, Afolabi A. Perception and practices during the COVID-19 pandemic in an urban community in Nigeria: a cross-sectional study. PeerJ. 2020;8:15. https://doi.org/10.7717/peerj.10038.

54. Kabito GG, Alemayehu M, Mekonnen TH, Daba Wami S, Azanaw J, Adane T, et al. Community's perceived high risk of coronavirus infections during early phase of epidemics are significantly influenced by socio-demographic background, in Gondar City, Northwest Ethiopia: a cross-sectional-study. PLoS ONE. 2020;15(11): e0242654. https://doi. org/10.1371/journal.pone.0242654.

55. Xu JW, Liu H, Ai D, Yu Y, Yu B. The Shan people's health beliefs, knowledge and perceptions of dengue in Eastern Shan Special Region IV, Myanmar. PLoS Negl Trop Dis. 2019;13(6): e0007498. https://doi.org/10. 1371/journal.pntd.0007498.

56. Ozioko KU, Okoye Cl, Obiezue RN, Agbu RA. Knowledge, attitudes, and behavioural risk factors regarding zoonotic infections among bushmeat hunters and traders in Nsukka, southeast Nigeria. Epidemiol Health. 2018;40: e2018025. https://doi.org/10.4178/epih.e2018025.

57. Akalu Y, Ayelign B, Molla MD. Knowledge, attitude and practice towards covid-19 among chronic disease patients at Addis Zemen hospital, Northwest Ethiopia. Infect Drug Resist. 2020;13:1949-60. https://doi. org/10.2147/IDR.S258736.

58. Berman A, Figueroa ME, Storey JD. Use of SMS-based surveys in the rapid response to the Ebola outbreak in Liberia: opening community dialogue. J Health Commun. 2017;22(sup1):15-23. https://doi.org/10. 1080/10810730.2016.1224279

59. Gidado S, Oladimeji AM, Roberts AA, Nguku P, Nwangwu IG, Waziri $\mathrm{NE}$, et al. Public knowledge, perception and source of information on Ebola virus disease-Lagos, Nigeria; September, 2014. PLoS Curr. 2015. https://doi.org/10.1371/currents.outbreaks.0b805cac244d700a47d6 a3713ef2d6db.

60. Jiang H, Shi G-Q, Tu W-X, Zheng C-J, Lai X-H, Li X-X, et al. Rapid assessment of knowledge, attitudes, practices, and risk perception related to the prevention and control of Ebola virus disease in three communities of Sierra Leone. Infect Dis Poverty. 2016;5(1):53. https://doi.org/10.1186/ s40249-016-0142-9.

61. Schmidt-Hellerau K, Winters M, Lyons P, Leigh B, Jalloh MB, Sengeh $P$, et al. Homecare for sick family members while waiting for medical help during the 2014-2015 Ebola outbreak in Sierra Leone: a mixed methods study. BMJ Glob Health. 2020;5(7): e002732. https://doi.org/ 10.1136/bmjgh-2020-002732.

62. Asnakew Z, Asrese K, Andualem M. Community risk perception and compliance with preventive measures for COVID-19 pandemic in Ethiopia. Risk Manag Healthc Policy. 2020;13:2887-97. https://doi.org/ 10.2147/rmhp.S279907.

63. Ghazi HF, Taher TMJ, Abdalqader MA, Raheema RH, Baobaid MF, Hasan TN. Knowledge, attitude, and practice regarding coronavirus disease-19: population-based study in Iraq. Open Access Maced J Med Sci. 2020;8(T1):137-41. https://doi.org/10.3889/oamjms.2020.4965.

64. Adhena G, Hidru HD. Knowledge, attitude, and practice of high-risk age groups to coronavirus disease-19 prevention and control in Korem district, Tigray, Ethiopia: cross-sectional study. Infect Drug Resist. 2020;13:3801-9. https://doi.org/10.2147/IDR.S275168.

65. Philavong C, Pruvot M, Reinharz D, Mayxay M, Khammavong K, Milavong $\mathrm{P}$, et al. Perception of health risks in Lao market vendors. Zoonoses Public Health. 2020;67(7):796-804. https://doi.org/10.1111/ zph.12759.

66. Kaponda P, Muthukrishnan S, Barber R, Holm RH. Drinking water quality and human dimensions of cholera patients to inform evidence-based prevention investment in Karonga District, Malawi. Water Sci Technol Water Supply. 2019;19(7):2079-87. https://doi.org/10.2166/ws.2019.086.

67. Ayegbusi T, Jegede SA, Aminu K, Oluwayelu DO. Perception and prevention practices against Ebola virus disease by bush meat handlers in Ibadan, Nigeria. Afr J Biomed Res. 2016;19(2):117-24.

68. Winters M, Jalloh MF, Sengeh P, Jalloh MB, Zeebari Z, Nordenstedt H. Risk perception during the 2014-2015 Ebola outbreak in Sierra Leone. BMC Public Health. 2020;20(1):1539. https://doi.org/10.1186/ s12889-020-09648-8.

69. Iorfa SK, Ottu IFA, Oguntayo R, Ayandele O, Kolawole SO, Gandi JC, et al. COVID-19 knowledge, risk perception, and precautionary behavior among Nigerians: a moderated mediation approach. Front Psychol. 2020;11:10. https://doi.org/10.3389/fpsyg.2020.566773.

70. Kasereka MC, Sawatzky J, Hawkes MT. Ebola epidemic in war-torn Democratic Republic of Congo, 2018: acceptability and patient satisfaction of the recombinant Vesicular Stomatitis Virus-Zaire Ebolavirus vaccine. Vaccine. 2019;37(16):2174-8. https://doi.org/10.1016/j.vaccine. 2019.03.004.

71. Khowaja ZA, Soomro MI, Pirzada AK, Yoosuf MA, Kumar V. Awareness of the pandemic H1N1 influenza global outbreak 2009 among medical students in Karachi, Pakistan. J Infect Dev Ctries. 2011;5(3):151-5. https://doi.org/10.3855/jidc.1247.

72. Bell SA, Munro-Kramer ML, Eisenberg MC, Williams G, Amarah P, Lori JR. "Ebola kills generations": qualitative discussions with Liberian healthcare providers. Midwifery. 2017;45:44-9. https://doi.org/10.1016/j.midw. 2016.12.005.

73. Abou-Abbas L, Nasser Z, Fares Y, Chahrour M, El Haidari R, Atoui R. Knowledge and practice of physicians during COVID-19 pandemic: a cross-sectional study in Lebanon. BMC Public Health. 2020;20(1):1474 https://doi.org/10.1186/s12889-020-09585-6.

74. Chaudhary FA, Ahmad B, Ahmad P, Khalid MD, Butt DQ, Khan SQ. Concerns, perceived impact, and preparedness of oral healthcare workers in their working environment during COVID-19 pandemic. J Occup Health. 2020;62(1): e12168. https://doi.org/10.1002/1348-9585.12168.

75. Girma S, Agenagnew L, Beressa G, Tesfaye Y, Alenko A. Risk perception and precautionary health behavior toward COVID-19 among health professionals working in selected public university hospitals in Ethiopia. PLoS ONE. 2020;15(10): e0241101. https://doi.org/10.1371/journal.pone. 0241101

76. Englert EG, Kiwanuka R, Neubauer LC. 'When I die, let me be the last.' Community health worker perspectives on past Ebola and Marburg outbreaks in Uganda. Glob Public Health. 2019;14(8):1182-92. https:// doi.org/10.1080/17441692.2018.1552306.

77. Iliyasu G, Ogoina D, Otu AA, Dayyab FM, Ebenso B, Otokpa D, et al. A multi-site knowledge attitude and practice survey of Ebola virus disease in Nigeria. PLoS ONE. 2015;10(8): e0135955. https://doi.org/10. 1371/journal.pone.0135955.

78. Fatiregun AA, Adeyemo AA, Olowookere SA. Willingness to receive pandemic influenza $\mathrm{A}(\mathrm{H} 1 \mathrm{~N} 1)$ vaccine among doctors and nurses in public health facilities in Ibadan, Nigeria. Vaccine. 2012;30(13):2315-9. https:// doi.org/10.1016/j.vaccine.2012.01.060.

79. Idris BJ, Inem V, Balogun M. Comparing the knowledge, attitude and practices of health care workers in public and private primary care facilities in Lagos State on Ebola virus disease. Pan Afr Med J. 2015;22(Supplement 1):19. https://doi.org/10.11694/pamj.supp.2015.22.1.6655.

80. Olowookere SA, Abioye-Kuteyi EA, Adepoju OK, Esan OT, Adeolu TM, Adeoye TK, et al. Knowledge, attitude, and practice of health workers in a tertiary hospital in Ile-Ife, Nigeria, towards Ebola viral disease. J Trop Med. 2015;2015: 431317. https://doi.org/10.1155/2015/431317.

81. Ekra KD, Cherif D, Kouassi DP, Konan YL, Coulibaly D, Traore Y, et al. Determinants of practices for dengue diagnosis among healthcare professionals working in public hospitals of Abidjan, Cote d'Ivoire. J Public Health Epidemiol. 2017;9(8):212-8. https://doi.org/10.5897/jphe2 017.0933.

82. Shakeel S, Rehman H, Hassali MA, Hashmi F. Knowledge, attitude and precautionary practices towards COVID-19 among healthcare professionals in Karachi, Pakistan. J Infect Dev Ctries. 2020;14(10):1117-24. https://doi.org/10.3855/jidc.12714.

83. Ogoina D, Oyeyemi AS, Ayah O, Onabor AA, Midia A, Olomo WT, et al. Preparation and response to the 2014 Ebola virus disease epidemic in Nigeria-the experience of a tertiary hospital in Nigeria. PLoS ONE. 2016;11 (10): e0165271. https://doi.org/10.1371/journal.pone.0165271.

84. Hoffman SJ, Silverberg SL. Delays in global disease outbreak responses: lessons from H1N1, Ebola, and Zika. Am J Public Health. 2018;108(3):329-33. https://doi.org/10.2105/ajph.2017.304245.

85. Wang C, O'Neill SM, Rothrock N, Gramling R, Sen A, Acheson LS, et al. Comparison of risk perceptions and beliefs across common chronic diseases. Prev Med. 2009;48(2):197-202. https://doi.org/10.1016/j.ypmed. 2008.11.008.

86. DiLorenzo TA, Schnur J, Montgomery GH, Erblich J, Winkel G, Bovbjerg $\mathrm{DH}$. A model of disease-specific worry in heritable disease: the influence of family history, perceived risk and worry about other 
illnesses. J Behav Med. 2006;29(1):37-49. https://doi.org/10.1007/ s10865-005-9039-y.

87. Erblich J, Bovbjerg DH, Norman C, Valdimarsdottir HB, Montgomery GH. It won't happen to me: lower perception of heart disease risk among women with family histories of breast cancer. Prev Med. 2000;31 (6):714-21. https://doi.org/10.1006/pmed.2000.0765.

88. Weinstein ND. Unrealistic optimism about future life events. J Pers Soc Psychol. 1980;39(5):806-20. https://doi.org/10.1037/0022-3514.39.5.806.

89. Gierlach E, Belsher BE, Beutler LE. Cross-cultural differences in risk perceptions of disasters. Risk Anal. 2010;30(10):1539-49. https://doi.org/ 10.1111/j.1539-6924.2010.01451.X.

90. Waters EA, Klein WM, Moser RP, Yu M, Waldron WR, McNeel TS, et al. Correlates of unrealistic risk beliefs in a nationally representative sample. J Behav Med. 2011;34(3):225-35. https://doi.org/10.1007/ s10865-010-9303-7.

91. Dolinski D, Dolinska B, Zmaczynska-Witek B, Banach M, Kulesza W. Unrealistic optimism in the time of coronavirus pandemic: may it help to kill, if so-whom: disease or the person? J Clin Med. 2020;9(5):1464. https:// doi.org/10.3390/jcm9051464.

92. Koh D, Lim MK, Chia SE, Ko SM, Qian F, Ng V, et al. Risk perception and impact of severe acute respiratory syndrome (SARS) on work and personal lives of healthcare workers in Singapore: what can we learn? Med Care. 2005;43(7):676-82. https://doi.org/10.1097/01.mlr.0000167181. 36730.cc.

93. Sultan MA, Løwe Sørensen J, Carlström E, Mortelmans L, KhorramManesh A. Emergency healthcare providers' perceptions of preparedness and willingness to work during disasters and public health emergencies. Healthcare. 2020. https://doi.org/10.3390/healthcare8040442.

94. O'Sullivan TL, Dow D, Turner MC, Lemyre L, Corneil W, Krewski D, et al. Disaster and emergency management: Canadian nurses' perceptions of preparedness on hospital front lines. Prehosp Disaster Med. 2008;23(3):s11-8.

95. Slovic P. The perception of risk. Risk, society, and policy series. Earthscan Publications; 2000. p. xxxvii, 473-xxxvii.

96. Covello VT, Peters RG, Wojtecki JG, Hyde RC. Risk communication, the West Nile virus epidemic, and bioterrorism: responding to the commnication challenges posed by the intentional or unintentional release of a pathogen in an urban setting. J Urban Health. 2001;78(2):382-91. https://doi.org/10.1093/jurban/78.2.382.

97. Bonem EM, Ellsworth PC, Gonzalez R. Age differences in risk: perceptions, intentions and domains. J Behav Decis Mak. 2015;28(4):317-30. https://doi.org/10.1002/bdm.1848

98. Gustafson PE. Gender differences in risk perception: theoretical and methodological perspectives. Risk Anal. 1998;18(6):805-11. https://doi. org/10.1023/b:rian.0000005926.03250.c0.

99. Wolff K, Larsen S, Øgaard T. How to define and measure risk perceptions. Ann Tour Res. 2019;79: 102759. https://doi.org/10.1016/j.annals. 2019.102759.

100. Boholm $\AA$. The cultural nature of risk: can there be an anthropology of uncertainty? Ethnos. 2003;68(2):159-78. https://doi.org/10.1080/00141 84032000097722

101. Wilson RS, Zwickle A, Walpole H. Developing a broadly applicable measure of risk perception. Risk Anal. 2019;39(4):777-91. https://doi. org/10.1111/risa.13207.

102. Waters EA, Hay JL, Orom H, Kiviniemi MT, Drake BF. "Don't know" responses to risk perception measures: implications for underserved populations. Med Decis Mak. 2013;33(2):271-81. https://doi.org/10. 1177/0272989x12464435.

103. Vinayak KN, Michael AV, Ford MA. Conceptualizing and measuring risk perceptions of skin cancer: a review. Calif J Health Promot. 2013;11(3):36-47. https://doi.org/10.32398/cjhp.v11i3.1540.

104. The World Bank. Classification of fragile and conflict-affected situations. In: Fragility, conflict and violence. https://www.worldbank.org/en/ topic/fragilityconflictviolence/brief/harmonized-list-of-fragile-situa tions. Accessed 16 Dec 2020.

105. World Health Organization. Addressing sex and gender in epidemicprone infectious diseases. Geneva: World Health Organization; 2007.

106. Darker C. Risk perception. In: Gellman MD, Turner JR, editors. Encyclopedia of behavioral medicine. New York: Springer; 2013. p. 1689-91.

107. Claude KM, Underschultz J, Hawkes MT. Social resistance drives persistent transmission of Ebola virus disease in Eastern Democratic Republic of Congo: a mixed-methods study. PLoS ONE. 2019;14(9): e0223104. https://doi.org/10.1371/journal.pone.0223104.

108. Coulibaly D, Nzussouo NT, Kadjo HA, Traore Y, Ekra DK, Cherif D, et al. Pandemic influenza A(H1N1) in cote d'Ivoire: health-care providers' knowledge of influenza and attitudes towards vaccination. J Infect Dev Ctries. 2013;7(7):499-506. https://doi.org/10.3855/jidc.2771.

109. Hakim M, Khattak FA, Muhammad S, Ismail M, Ullah N, Atiq Orakzai M, et al. Access and use experience of personal protective equipment among frontline healthcare workers in Pakistan during the COVID-19 emergency: a cross-sectional study. Health Secur. 2020. https://doi.org/ 10.1089/hs.2020.0142.

110. Irwin KL, Jalloh MF, Corker J, Alpha Mahmoud B, Robinson SJ, Li W, et al. Attitudes about vaccines to prevent Ebola virus disease in Guinea at the end of a large Ebola epidemic: results of a national household survey. Vaccine. 2017;35(49):6915-23. https://doi.org/10.1016/j.vaccine.2017. 06.026 .

111. Jalloh MF, Li W, Bunnell RE, Ethier KA, O'Leary A, Hageman KM, et al. Impact of Ebola experiences and risk perceptions on mental health in Sierra Leone, July 2015. BMJ Glob Health. 2018;3(2): e000471. https:// doi.org/10.1136/bmjgh-2017-000471.

112. Mohamed MMG, Shwaib HM, Fahim MM, Ahmed EA, Omer MK, Monier $I A$, et al. Ebola hemorrhagic fever under scope, view of knowledge, attitude and practice from rural Sudan in 2015. J Infect Public Health. 2017;10(3):287-94. https://doi.org/10.1016/j.jiph.2016.05.016.

113. Murele B, Vaz R, Gasasira A, Mkanda P, Erbeto T, Okeibunor J. Vaccine perception among acceptors and non-acceptors in Sokoto State, Nigeria. Vaccine. 2014;32(26):3323-7. https://doi.org/10.1016/j.vaccine.2014. 03.050.

114. Sengeh P, Jalloh MB, Webber N, Ngobeh I, Samba T, Thomas H, et al. Community knowledge, perceptions and practices around COVID19 in Sierra Leone: a nationwide, cross-sectional survey. BMJ Open. 2020;10(9): e040328. https://doi.org/10.1136/bmjopen-2020-040328.

115. Tadesse DB, Gebrewahd GT, Demoz GT. Knowledge, attitude, practice and psychological response toward COVID-19 among nurses during the COVID-19 outbreak in northern Ethiopia, 2020. New Microbes New Infect. 2020;38: 100787. https://doi.org/10.1016/j.nmni.2020.100787.

116. ul Haq S, Shahbaz P, Boz I. Knowledge, behavior and precautionary measures related to COVID-19 pandemic among the general public of Punjab province, Pakistan. J Infect Dev Ctries. 2020;14(8):823. https:// doi.org/10.3855/jidc.12851.

Ready to submit your research? Choose BMC and benefit from

- fast, convenient online submission

- thorough peer review by experienced researchers in your field

- rapid publication on acceptance

- support for research data, including large and complex data types

- gold Open Access which fosters wider collaboration and increased citations

- maximum visibility for your research: over 100M website views per year

At BMC, research is always in progress.

Learn more biomedcentral.com/submissions 